UNIVERSIDADE DE SÃO PAULO

FACULDADE DE MEDICINA DE RIBEIRÃO PRETO

Alexandre Pavan Garieri

Produção de VEGF e HIF-1 $\alpha$ em Pacientes com Carcinoma de Mama Localmente Avançado submetidas à Quimioterapia Neoadjuvante

RIBEIRÃO PRETO 
Alexandre Pavan Garieri

\title{
Produção de VEGF e HIF-1 $\alpha$ em pacientes com carcinoma de mama localmente avançado submetidas à quimioterapia neoadjuvante
}

\author{
Dissertação apresentada à Faculdade de Medicina de Ribeirão \\ Preto da Universidade de São Paulo, para concorrer ao título de \\ Mestre, pelo curso de Pós-Graduação em Ciências Médicas - \\ Área de concentração: Mastologia.
}

Orientador: $\quad$ Prof. Dr. Heitor Ricardo Cosiski Marana

RIBEIRÃO PRETO

2008 


\section{Índice de páginas}

1. Resumo 4

2. Abstract 6

3. Introdução $\quad 8$

4. Objetivos 13

5. Casuística e Metodologia 14

5.1 Critérios de Seleção de Pacientes 14

5.2 Características das Pacientes 15

$\begin{array}{lll}5.3 & \text { Ambiente do projeto } & 17\end{array}$

$\begin{array}{ll}5.4 \text { Coleta de Material } & 17\end{array}$

$\begin{array}{lll}5.5 & \text { Tratamento } & 18\end{array}$

5.6 Critérios de Resposta 18

$\begin{array}{lll}5.7 \text { Toxicidade } & 19\end{array}$

5.8 Processamento do material 22

5.9 Análise Estatística 23

6. Resultados 25

6.1 Avaliações clínicas 25

6.2 Avaliações laboratoriais 30

7. Discussão 42

8. Conclusões 49

9. Bibliografia $\quad 50$

10. Apêndice 55

11. Termo de consentimento livre e esclarecido 56

12. Esclarecimento ao sujeito de pesquisa $\quad 57$ 


\section{Resumo}

PROPOSTA: Determinar o valor prognóstico e preditivo do VEGF (vascular endothelial growth factor) e do HIF-1 $\alpha$ (Hypoxia-inducible factor-1) em relação à sobrevida livre de doença (SLD) e sobrevida global (SG) em pacientes com carcinoma de mama localmente avançado (CMLA) tratadas primariamente pela quimioterapia neoadjuvante.

MATERIALS E METODOS: VEGF e HIF foram quantificados consecutivamente em plasma de 36 pacientes com CMLA pelo método de ELISA (enzyme labeling immunoassay absorbant) para o VEGF 165 e o HIF-1 $\alpha$. O tratamento neoadjuvante foi realizado em todas as pacientes com docetaxel e epirrubicina. O tempo médio de seguimento foi de 56 meses.

RESULTADOS: Uma análise univariada demonstrou que o HIF-1 $\alpha$ está significantemente relacionado à SLD $(\mathbf{P}=.0238)$ e à SG $(\mathbf{P}=.0121)$ com as pacientes HER-2 positivas. Não houve diferença significante para a SLD ou SG no que diz respeito aos receptores de hormônio, comprometimento axilar ou grau tumoral. Os valores de VEGF foram maiores no grupo de pacientes $\mathrm{RE}+$ do que no grupo RE negativo $(\mathbf{P}=.01)$. Inversamente os valores de HIF-1 $\alpha$ foram menores no grupo RE+ comparados ao grupo RE - $(\mathbf{P}=.02)$. Pacientes com recorrência óssea apresentaram uma tendência a apresentarem valores de VEGF menores (media, $175.7 \mathrm{pg} / \mathrm{ml}$ ) do que aquelas com recorrência visceral (441 pg/ml). Uma análise multivariada demonstrou o comprometimento axilar $(\mathbf{P}=.0004)$, receptores de estrógeno $(\mathrm{ER})(\mathbf{P}<.0001)$, e tamanho do tumor $(\mathbf{P}=.0085)$ como fatores independentes de SLD. O HIF-1 $\alpha$ foi tido como um fator independente preditivo de SG (P =.0180). Não houve diferença estatisticamente significante entre os valores plasmáticos de HIF-1 $\alpha$ ou VEGF nos períodos pré e pós quimioterapia. CONCLUSÕES: Os resultados sugerem que o nível plasmático do HIF-1 $\alpha$ é preditivo de SLD e SG nas pacientes com CMLA apresentando uma sobreposição as pacientes HER-2 positivas. As dosagens de VEGF podem ser preditivas de resposta e prognóstico no tratamento neoadjuvante, mas são necessários novos estudos prospectivos comparados ao HIF-1 $\alpha$ para conclusões mais consistentes. 


\begin{abstract}
PURPOSE: To determine the predictive and prognostic value of vascular endothelial growth factor (VEGF) and Hypoxia-inducible factor-1 (HIF-1 $\alpha$ ) for relapse-free survival (RFS) and overall survival (OS) in locally advanced breast cancer (LABC) primarily submitted to neoadjuvant chemotherapy.

MATERIALS AND METHODS: VEGF and HIF were quantitatively measured in plasma sample from 36 consecutive patients with LABC using an enzyme immunoassay for human VEGF 165 and HIF-1 $\alpha$. Neoadjuvant treatment was given to all patients as docetaxel and epirrubicin. The follow-up median time was 56 months.

RESULTS: Univariate analysis showed that HIF- $1 \alpha$ is a significant predictor of RFS $(\mathbf{P}=.0238)$ and OS $(\mathbf{P}=$ 0121) in HER-2 positive patients. No significant difference was seen in RFS or OS related to hormonal receptor, axillary status or tumoral grade. The VEGF level was higher in the group of patients who ER was positive than ER negative $(\mathbf{P}=.01)$. On the other hand, the HIF-1 $\alpha$ level is higher in ER negative patients than ER positive ( $\mathrm{P}=$.02). Patients with bone recurrences tended to have lower VEGF plasma level (median, $175.7 \mathrm{pg} / \mathrm{ml}$ ) than patients with visceral metastasis $(441 \mathrm{pg} / \mathrm{ml})$. Multivariate analysis showed nodal status $(\mathbf{P}=.0004)$, estrogen receptor $(\mathrm{ER})$ status $(\mathbf{P}<.0001)$, and tumor size $(\mathbf{P}=.0085)$ to be independent predictors of RFS. HIF-1 $\alpha$ was found to be an independent predictor of OS $(\mathbf{P}=.0180)$. No statistically differences were observed related to pre and post chemotherapy period in HIF-1 $\alpha$ or VEGF measurements. CONCLUSION: The results suggest that high level of plasma HIF-1 $\alpha$ is associated to HER-2 over expression and they are major predictive factors of RFS and OS in LABC. VEGF content might also predict outcome after neoadjuvant treatment, however further studies in a prospective setting with HIF-1 $\alpha$ homologous treatments are required.
\end{abstract}




\section{Introdução}

O câncer é um problema de saúde pública, com aproximadamente 11 milhões de casos novos em todo o mundo em 2006, os quais apresentaram 7 milhões de mortes. Para o ano de 2020 a previsão é de 16 milhões de casos novos e 12 milhões de óbitos, segundo relatório do UICC/2005. Destes, 60\% ocorrerão em países em desenvolvimento.

O câncer de mama é a principal neoplasia maligna entre as mulheres ocidentais, e uma das principais causas de morte. As estatísticas indicam um aumento de freqüência da neoplasia tanto nos países desenvolvidos quanto nos países em desenvolvimento. Nos EUA, foi estimado para 2006, 214.000 mulheres com esta patologia (Bevers, TB et al, 2007). No Brasil, o tumor de mama é a principal causa de mortes entre as mulheres, contabilizando mais de nove mil óbitos por ano, segundo dados de 2006 (INCA, 2006). Este também é o segundo tipo mais incidente de câncer, contabilizando cerca de 50 mil casos, sendo ultrapassado apenas pelos tumores de pele não melanoma. Apenas no estado de São Paulo, a estimativa para 2006, revela aproximadamente 75,45 casos novos para cada 100.000 mulheres.

Apesar das políticas de incentivo ao rastreamento por mamografia para detecção precoce do câncer de mama, aproximadamente $10 \%$ dos tumores, mundialmente, são diagnosticados como câncer de mama localmente avançado, com aumento do risco de metástases subseqüentes e prognóstico mais sombrio (Ahern et al, 2005). Diferente de países como os EUA, onde há um aumento da incidência, mas diminuição da mortalidade por câncer de mama, o Brasil ainda apresenta elevação nas taxas de mortalidade pela neoplasia, principalmente pela detecção tardia da doença, ocorrendo em aproximadamente metade dos casos.

Nas pacientes portadoras de doença localmente avançada, a terapia multidisciplinar, com combinação de quimioterapia, radioterapia e cirurgia, torna-se obrigatória (Ahern et al, 2005). Como opção de tratamento, a fim de iniciar o tratamento sistêmico mais precoce, diminuir o tamanho tumoral e reduzir a extensão da cirurgia, utiliza-se a quimioterapia neoadjuvante. Os dados ainda contraditórios favorecem a 
hipótese de que não há aumento da sobrevida global e do tempo livre de doença nas pacientes usuárias de quimioterapia neoadjuvante comparadas àquelas submetidas à quimioterapia adjuvante, exceção feita àquelas que apresentam resposta patológica completa (Bear HD, et al 2006).

As premissas que corroboram para o uso da terapêutica sistêmica primária são: esterilizar áreas de micrometástases, que poderiam sofrer estímulos após a retirada do tumor primário, através do processo de angiogênese; aumentar as taxas de cirurgias conservadoras com redução dos riscos de recidiva local e finalmente, testar, in vivo, o efeito dos quimioterápicos (Sachelarie et al, 2006).

Apesar dos conhecimentos prévios oriundos do largo emprego da quimioterapia neoadjuvante, ainda desconhecem-se quais são as pacientes que verdadeiramente se beneficiam com a quimioterapia primária e quais os regimes mais apropriados. O conhecimento dos mecanismos intra-tumorais que regulam o crescimento tumoral, sua interação com o estroma subjacente e com o infiltrado de células inflamatórias, podem cooperar para responder essas questões, fornecendo marcadores preditivos de resposta terapêutica e prognósticos de seguimento, além de propiciar alvos para novas terapias.

Como outros tumores sólidos, os tumores de mama necessitam de um microambiente que promova angiogênese e linfangiogênese, que não apenas mantém a viabilidade tumoral e seu crescimento, mas que também contribua com a disseminação da doença. Esse mecanismo apresenta estreita relação com o prognóstico da doença (Folkman J., 1998).

Enquanto a vasculatura de um adulto normal encontra-se quiescente, com divisões das células endoteliais a cada dez anos, os tumores apresentam constante formação e remodelação vascular. Alguns dos fatores atuantes na angiogênese e linfangiogênese tumoral já são conhecidos. O HIF (fator indutor de hipóxia) e o HIF1- $\alpha$ (fator de resposta a hipóxia), superexpressos em carcinomas ductais de mama, induzem diretamente a expressão de mediadores pró-angiogênicos, notadamente o fator de crescimento endotelial vascular (VEGF) e seus receptores (Boudreau et al, 2003).

O VEGF é um potente peptídeo angiogênico com ação no desenvolvimento de stem cell hematopoiéticas, remodelação da matrix extracelular e regeneração de citocinas inflamatórias. É fator de crescimento e permeabilidade vascular. A família VEGF é formada pelo VEGF-A (VEGF), PIGF (fator de 
crescimento placentário), VEGF-B, VEGF-C e VEGF-D. O VEGF-A atua através dos receptores VEGFR-1 e VEGFR-2, PIGF e VEGF-B através de VEGFR-1, VEGF-C através dos receptores VEGFR-2 e VEGFR-3 e o VEGF-D através do VEGFR-1 e VEGFR-2. O receptor VEGFR-3/FLT-4 e seus ligantes, VEGF-C e VEGF-D, estão relacionados à linfangiogênese e metástases linfáticas em vários tipos de tumores sólidos (Pradeep et al, 2005).

Os fatores VEGF-C e VEGF-D são produzidos pelos macrófagos associados ao tumor (TAMs) ativados, que também expressão o receptor VEGFR-3. Estudos com tumores sólidos, com carcinoma espinocelular de colo uterino, evidenciaram que a densidade microvascular linfática e a superexpressão destes dois fatores tem relação com a disseminação linfática e prognóstico dos doentes (Schoppmann et al, 2002).

O uso de anticorpos monoclonais, como o bevacizumabe (Avastin®), dirigido especificamente contra o VEGF-A, impedindo a ligação da isoforma ao seu receptor, em estudos pré-clínicos e em pacientes com doença metastática, associados aos quimioterápicos, apresentam resultados animadores no controle tumoral (Rosen et al, 2007).

Este conjunto de evidências torna claro que a neoangiogênese, a presença de macrófagos associados ao tumor (TAMs), a expressão de VEGF-C e VEGF-D e a densidade microvascular linfática exerce atividade sobre a disseminação linfática dos tumores de mama, correlacionando-se com o status axilar e com o prognóstico das pacientes. Em outra análise da expressão do HIF-1 $\alpha$, observou-se uma correlação crescente entre a sua expressão e o aumento do estádio clínico, e portanto, da extensão do tumor, assim como do aumento da sua indiferenciação histológica (Bos et al, 2001).

Como estes fatores são solúveis e detectáveis no plasma de pacientes com carcinoma, a sua avaliação e correlação com o comportamento do tumor frente ao tratamento neoadjuvante de carcinomas localmente avançados de mama, poderiam ser utilizados como fatores prognósticos e/ou preditivos de resposta, a fim de selecionar grupos de pacientes que pudessem se beneficiar desta forma de tratamento específica.

Dentre os fatores conhecidos tanto o VEGF, como o HIF1- $\alpha$ são passíveis de detecção plasmática, e guardam uma estreita relação com prognóstico em situações de carcinomas da mama (Bos et al, 2001). A detecção de valores elevada de VEGF plasmático está associado a um mau prognóstico, porém em 
alguns casos de VEGF elevados com bom prognóstico, o que podemos observar é que o HIF é encontrado em baixas concentrações. Assim, parece que a detecção de ambos os fatores angiogênico e de hipóxia intratumoral são necessários para a geração de clones de células tumorais que se perpetuarão em casos mais agressivos (Kimbro \& Simons, 2006).

Ao lidarmos com carcinomas localmente avançados, temos um período de crescimento tumoral mais prolongado, e um prognóstico mais reservado, provavelmente secundário a existência de clones altamente angigogênicos e produzidos em uma atmosfera de hipóxia relativa (Furstenberger et al., 2006). Estas células tumorais poderiam ser tratadas pela quimioterapia neoadjuvante, assim como as micrometástases decorrentes deste tumor. Desta forma, as detecções plasmáticas do VEGF e do HIF-1 $\alpha$ poderiam ser utilizadas como fatores prognósticos em carcinomas de mama localmente avançados, tanto em termos preditivos como prognósticos.

Este estudo visa estabelecer tanto esta relação de detecção plasmática destes fatores, quanto aos valores de corte para fins de análise experimental. Secundariamente faremos a correlação com fatores clínicos, histopatológicos e de imunohistoquímica com as detecções realizadas de fatores angiogênicos e de hipóxia tumoral, e aos efeitos dos quimioterápicos sobre eles, com a finalidade de oferecer dados consistentes ao benefício da quimioterapia e potencializar estratégias de tratamento para pacientes com neoplasias malignas de mama.

\section{Objetivos}

Este estudo tem por objetivo:

1) Dosar os fatores angiogênico e de hipóxia no plasma periférico, colhido antes do início do tratamento e após a terapia neo-adjuvante. 
2) Correlacionar os achados com a resposta clínica e histopatológica ao tratamento neoadjuvante.

3) Correlacionar as dosagens plasmáticas com os fatores prognósticos clínicos, histopatológicos e de imunohistoquímica das pacientes estudadas.

4) Avaliar o padrão de curvas de sobrevida e intervalo livre de doenças nos subgrupos desta avaliação.

\section{Casuística e Metodologia}

\subsection{Critérios de Seleção de Pacientes}

Foram incluídas para a participação neste projeto as pacientes com tumores localmente avançados de mama atendidas no Ambulatório de Mastologia do Hospital das Clínicas da Faculdade de Medicina de Ribeirão Preto da Universidade de São Paulo (HC-FMRP-USP), no período de 2001 a 2006. Todas apresentavam o diagnóstico de carcinoma de mama, obtido por biópsia, tumor palpável e deveriam ter recebido tratamento neoadjuvante com pelo menos dois ciclos de quimioterapia com o esquema de Docetaxel e Epirrubicina. Foram incluídas as que apresentassem doença no estádio clínico IIA a IIIC, independente de idade, raça, status menopausal ou tipo histológico.

Pacientes que após avaliação histopatológica do material obtido pela biópsia tiveram o diagnóstico de patologia mamária benigna foram excluídas do projeto. A realização de qualquer terapia antitumoral previamente ao procedimento diagnóstico ou quimioterapia primária também serviu como critério de exclusão. Além destas, foram ainda excluídas as pacientes que tivessem o diagnóstico de doença metastática durante o tratamento neoadjuvante, bem como as que se recusaram a participar do estudo ou que abandonaram o seguimento ao longo do mesmo.

O estudo foi aprovado pelo Comitê de Ética em Pesquisa do HC-FMRP-USP, de acordo com o processo HCRP nº 2519/2003. 


\subsection{Características das Pacientes}

Trinta seis mulheres com diagnóstico histológico de carcinoma mamário invasor, tumores localmente avançado e indicação de tratamento primário com quimioterapia neoadjuvante foram avaliadas durante o presente estudo.

A média de idade das pacientes foi de 49 anos $(29$ - 63) e o número de ciclos de quimioterapia neoadjuvante variou de 2 a 5 ciclos, com média de 3 ciclos por paciente.

De todas as mulheres, 32 eram portadoras de carcinoma ductal invasor e o restante outros subtipos histológicos especiais. Dados referentes ao estádio clínico, status menopausal, grau tumoral e análise imunohistoquímica encontram-se na tabela 1.

Tabela 1. Características das pacientes com carcinoma de mama submetidas à quimioterapia neoadjuvante. 


\begin{tabular}{|c|c|c|}
\hline Características & $\mathrm{n}=36$ & $(\%)$ \\
\hline Média de Idade (variação) & $47(29-63)$ & \\
\hline Ciclos de QTX (variação) & $3(2-5)$ & \\
\hline \multicolumn{3}{|l|}{ Status menopausal } \\
\hline Pré & 19 & 52.7 \\
\hline Pos & 17 & 47.3 \\
\hline \multicolumn{3}{|l|}{ Estádio clínico } \\
\hline IIA & 4 & 11.1 \\
\hline IIB & 13 & 36.1 \\
\hline IIIA & 4 & 11.1 \\
\hline IIIB & 13 & 36.1 \\
\hline IIIC & 2 & 5.6 \\
\hline \multicolumn{3}{|l|}{ Tipo histológico } \\
\hline Ductal & 34 & 94.4 \\
\hline Outros & 2 & 5.6 \\
\hline \multicolumn{3}{|l|}{ Grau Histológico } \\
\hline I & 7 & 19.4 \\
\hline II & 22 & 61.2 \\
\hline III & 7 & 19.4 \\
\hline \multicolumn{3}{|l|}{ Receptores Hormonais } \\
\hline $\mathrm{RE} / \mathrm{RP}+$ & 29 & 80.5 \\
\hline RE/RP - & 7 & 19.5 \\
\hline
\end{tabular}

\subsection{Ambiente do Projeto}

O projeto foi realizado no departamento de Ginecologia e Obstetrícia do HC-FMRP-USP em colaboração com o laboratório de Imunologia Básica do Prof. João Santana da Silva do Departamento de 
Imunologia, Parasitologia e Microbiologia da Faculdade de Medicina de Ribeirão Preto da Universidade de São Paulo.

\subsection{Coleta de Material}

Amostras do tumor primário de mama e $5 \mathrm{ml}$ de sangue periférico heparinizado foram obtidos das pacientes submetidas a procedimento cirúrgico diagnóstico no HC-FMRP-USP. Todas as pacientes foram informadas do estudo, e obtidos consentimentos pós-informados aprovados pelo comitê de ética em pesquisa desta instituição.

As amostras foram obtidas assepticamente no ato cirúrgico a partir da amostra inicial enviada para a rotina histológica, a saber, no momento da biópsia incisional pré quimioterapia e da tumorectomia ou mastectomia pós quimioterapia. Áreas necróticas ou qualquer gordura ao redor do tumor foram cuidadosamente removidas antes da preparação histológica.

O sangue periférico foi centrifugado e o plasma aliquotado em tubos de Eppendorf e congelados em freezer a menos $20^{\circ} \mathrm{C}$. Todas as amostras foram descongeladas e processadas simultaneamente ao final do período de coleta.

\subsection{Tratamento}

As pacientes receberam: Docetaxel na dose de $75 \mathrm{mg} \mathrm{m}^{-2}$ em infusão contínua em 1 hora em solução fisiológica, e Epirrubicina na dose de $60 \mathrm{mg} \mathrm{m}^{-2}$ em infusão contínua em 1 hora em solução fisiológica a seguir, a cada 21 dias.

Pré-medicação foi administrada com o objetivo de evitar qualquer reação alérgica possível dos pacientes ao Docetaxel: $10 \mathrm{mg}$ de Dexametasona 30 minutos antes do início da infusão. No domicílio, 2 dias antes as pacientes foram orientadas a ingerir Maleato de Dextroclorfeniranamina $2 \mathrm{mg}$ de $8 / 8$ horas e Dexametasona $4 \mathrm{mg}$ de 8/8 horas via oral com o objetivo de evitar rash cutâneo e retenção de fluido. 
Tendo ocorrido eventos de grau maior que II, mielossupressão, neuropatia, neurite ou efeitos gastrotóxicos (Classificação da OMS), o tratamento foi adiado até a recuperação. As doses de ambas as drogas permaneceram estáveis.

\subsection{Critérios de Resposta}

Antes de cada ciclo de tratamento as pacientes tiveram a resposta ao tratamento avaliado. As respostas foram categorizadas como segue, de acordo com critérios padrão da UICC - International Union Against Câncer (Hayward et al, 1977):

1) Resposta Completa: definida como desaparecimento completo de toda evidência de doença clínica.

2) Resposta Parcial: definida como diminuição de mais de $50 \%$ no produto das medidas dos maiores eixos perpendiculares das lesões.

3) Resposta Menor: uma diminuição de 25-50\%, sem satisfazer o critério de resposta parcial.

4) Progressão: aumento do volume do tumor.

\subsection{Toxicidade}

A Toxicidade foi avaliada de acordo com critérios da OMS (Miller et al, 1981). 


\section{WHO (World Health Organization) Toxicity Criteria by Grade}

\begin{tabular}{|c|c|c|c|c|c|}
\hline Toxicity & Grade0 & Grade1 & Grade2 & Grade3 & Grade4 \\
\hline WBC (x103/l) & 4 & $3.0-3.9$ & $2.0-2.9$ & $1.0-1.9$ & $<1.0$ \\
\hline Platelets (x103/l) & WNL & 75.0 - normal & $50.0-74.9$ & $25.0-49.9$ & $<25.0$ \\
\hline Haemoglobin (g/dl) & WNL & 10.0 - normal & $8.0-9.9$ & $6.5-7.9$ & $<6.5$ \\
\hline Granulocytes/ Bands (x103/l) & 2 & $1.5-1.9$ & $1.0-1.4$ & $0.5-0.9$ & $<0.5$ \\
\hline Lymphocytes (x103/l) & 2 & $1.5-1.9$ & $1.0-1.4$ & $0.5-0.9$ & $<0.5$ \\
\hline Haemorrhage & None & mild, no & $\begin{array}{l}\text { gross, } 1 \text { - } 2 \text { units } \\
\text { transfusion per episode }\end{array}$ & $\begin{array}{l}\text { gross, } 3 \text { - } 4 \text { units } \\
\text { transfusion p.e. }\end{array}$ & $\begin{array}{l}\text { massive, }>4 \text { units } \\
\text { transfusion p.e. }\end{array}$ \\
\hline Fibrinogen & WNL & $0.99-0.75 \times \mathrm{N}$ & $0.74-0.50 \times \mathrm{N}$ & $0.49-0.25 \times \mathrm{N}$ & $<0.25 \times \mathrm{N}$ \\
\hline Prothrombin time(Quick) & WNL & $1.01-1.25 \times \mathrm{N}$ & $1.26-1.50 \times \mathrm{N}$ & $1.51-2.00 \times \mathrm{N}$ & $>2.00 \times \mathrm{x} \mathrm{N}$ \\
\hline Partial thrombo- plastin time & WNL & $1.01-1.66 \times \mathrm{N}$ & $1.67-2.33 \times \mathrm{N}$ & $2.34-3.00 \times \mathrm{N}$ & $>3.00 \times \mathrm{N}$ \\
\hline Hyperglycaemia (mg/dl) & $<116$ & $116-160$ & $161-250$ & $251-500$ & $>500$ or ketoacidose \\
\hline Hypoglycaemia (mg/dl) & $>64$ & $55-64$ & $40-54$ & $30-39$ & $<30$ \\
\hline Amylase & WNL & $<1.5 \times \mathrm{N}$ & $1.5-2.0 \times \mathrm{N}$ & $2.1-5.0 \mathrm{~N}$ & $>5.0 \times \mathrm{N} \mathrm{N}$ \\
\hline Hypercalcaemia (mg/dl) & $<10.6$ & $10.6-11.5$ & $11.6-12.5$ & $12.6-13.4$ & 13.5 \\
\hline Hypocalcaemia (mg/dl) & $>8.4$ & $8.4-7.8$ & $7.7-7.0$ & $6.9-6.1$ & 6 \\
\hline Hypomagnesaemia (mg/dl) & $>1.4$ & $1.4-1.2$ & $1.1-0.9$ & $0.8-0.6$ & 0.5 \\
\hline Náusea & None & $\begin{array}{l}\text { able to eat reasonable } \\
\text { intake }\end{array}$ & $\begin{array}{l}\text { intake significantly } \\
\text { decreased but can eat }\end{array}$ & no significant intake & - \\
\hline Vomiting & None & 1 episode in $24 \mathrm{hrs}$ & $2-5$ episodes in $24 \mathrm{hrs}$ & 6-10 episodes/24hs & $\begin{array}{l}>10 \text { episodes in } 24 \mathrm{hrs} \text { or } \\
\text { requiring parenteral support }\end{array}$ \\
\hline Diarrhoea & None & $\begin{array}{l}\text { increase of } 2-3 \text { stools / } \\
\text { day over pre-Rx }\end{array}$ & $\begin{array}{l}\text { increase of } 4 \text { - } 6 \text { stools / } \\
\text { day, or nocturnal stools, or } \\
\text { moderate cramping }\end{array}$ & $\begin{array}{l}\text { increase of } 7-9 \text { stools / } \\
\text { day, or incontinence, or } \\
\text { severe cramping }\end{array}$ & $\begin{array}{c}\text { increase of }>10 \text { stools/day } \\
\text { or grossly bloody diarrhoea, } \\
\text { or need for parenteral } \\
\text { support }\end{array}$ \\
\hline Stomatitis & None & $\begin{array}{l}\text { painless ulcers, } \\
\text { erythema, or mild } \\
\text { soreness }\end{array}$ & $\begin{array}{l}\text { painful erythema, oedema, } \\
\text { or ulcers but can eat solids }\end{array}$ & $\begin{array}{l}\text { painful erythema, } \\
\text { oedema, or ulcers and } \\
\text { cannot eat solids }\end{array}$ & $\begin{array}{l}\text { requires parenteral or } \\
\text { enteral support for } \\
\text { alimentation }\end{array}$ \\
\hline Bilirubin $(\mathrm{N}=17 \mu \mathrm{mol} / \mathrm{L})$ & WNL & ---- & $<1.5 \times \mathrm{N}$ & $1.5-3.0 \times \mathrm{N}$ & $>3.0 \times \mathrm{N} \mathrm{N}$ \\
\hline Transaminase (SGOT, SGPT) & WNL & $2.5 \times \mathrm{N}$ & $2.6-5.0 \times \mathrm{N}$ & $5.1-20.0 \times \mathrm{N}$ & $>20.0 \times \mathrm{N}$ \\
\hline Liver- clinical & $\begin{array}{l}\text { No change from } \\
\text { baseline }\end{array}$ & ---- & ----- & precoma & hepatic coma \\
\hline Creatinine & WNL & $<1.5 \times \mathrm{N}$ & $1.5-3.0 \times \mathrm{N}$ & $3.1-6.0 \times \mathrm{N}$ & $>6.0 \times \mathrm{x} \mathrm{N}$ \\
\hline Haematuria & Negative & microscopic only & $\begin{array}{c}\text { gross, no clots no Rx } \\
\text { needed }\end{array}$ & $\begin{array}{l}\text { gross and clots bladder } \\
\text { irrigation }\end{array}$ & $\begin{array}{l}\text { requires transfusion or } \\
\text { cystectomy }\end{array}$ \\
\hline Weight gain/ loss & $<5.0 \%$ & $5.0-9.9 \%$ & $10.0-19.9 \%$ & $20.00 \%$ & ----- \\
\hline Pulmonary & $\begin{array}{l}\text { none or no } \\
\text { change }\end{array}$ & $\begin{array}{l}\text { asymptomatic, with } \\
\text { abnormal- ity in PFTs }\end{array}$ & $\begin{array}{l}\text { dyspnoea on significant } \\
\text { exertion }\end{array}$ & $\begin{array}{l}\text { dyspnoea at normal } \\
\text { level of activity }\end{array}$ & dyspnoea at rest \\
\hline Cardiac arrhythmias & None & $\begin{array}{l}\text { asymptomatic, transient, } \\
\text { requiring no therapy }\end{array}$ & $\begin{array}{l}\text { recurrent or persistent, no } \\
\text { therapy required }\end{array}$ & requires treatment & $\begin{array}{l}\text { requires moni- toring; or } \\
\text { hypo- tension, or ventricular } \\
\text { tachycardia or fibrillation }\end{array}$ \\
\hline Cardiac function & None & $\begin{array}{l}\text { asymptomatic, decline } \\
\text { of resting ejection }\end{array}$ & $\begin{array}{l}\text { asymptomatic, decline of } \\
\text { resting ejection fraction by }\end{array}$ & $\begin{array}{l}\text { mild CHF, responsive to } \\
\text { therapy }\end{array}$ & severe of refractory CHF \\
\hline
\end{tabular}




$\begin{array}{cc}\text { Cardiac ischaemia } & \text { None } \\ \text { Cardiac- pericardial } & \text { None } \\ \text { Hypertension } & \begin{array}{c}\text { none or no } \\ \text { change }\end{array}\end{array}$

Hypotension

Neuro: sensory

Neuro: motor

Neuro: cortical

Neuro: cerebellar

Neuro: mood

Neuro: headache

Neuro: constipation

Neuro: hearing

Neuro: vision

Pain

Skin

Alopecia

Allergy

Local

Fever of unknown origin

Infection

Asthenia

Chills

Peripheral oedema

Anorexia

none or no change

\section{None}

no change

$$
\text { None }
$$

none or no change

none or no

none or no

change

None

none or no

change

no loss

None

None

None

None fraction by less than 20 more than $20 \%$ of baseline $\%$ of baseline value

non-specific T- wave

$$
\text { flattening }
$$

asymptomatic effusion, no itervention required asymptomatic, transient increase by greater than

$20 \mathrm{~mm} \mathrm{Hg}$ (D) or to > $150 / 100$ if previously WNL. No treatment required.

changes requiring no therapy (incl- uding transient orthostatic

$$
\text { hypo- tension) }
$$

none or no mild paraesthesias; los change of deep tendon reflexes subjective weak- ness;
no objective findings

mild somnolence or agitation

slight incoordination, dysdiadochokinesia

$$
\begin{gathered}
\text { Mild anxiety or } \\
\text { depression }
\end{gathered}
$$

mild

mild

asymptomatic, hearing loss on audiometry only

value

asymptomatic, ST and T

wave changes suggesting ischaemia

pericarditis (rub, chest

pain, ECG changes)

recurrent or persistent

increase by greater than 20

mm HG (D) or to > $150 /$

100 if previously WNL.

No treatment required. hospitalisation ment of function

intention tremor, nystagmus

moderate anxiety or depression

moderate or severe but transient

moderate

tinnitus moderate

scattered macular or

papular eruption or

scattered macular ot papular eruption or erythema that is asymptomatic

mild hair loss

transient rash, drug fever $<38$ oC

pain

$$
37.1 \text { - 38.0o C } 98.7 \text { o - }
$$

mild requires fluid replacement requires therapy and or other therapy but not hospitalisation; resolves

mild or moderate objective severe objective sensory sensory loss moderate loss or paraesthesias that paraesthesias interfere with function

mild objective weakness objektive weak- ness

without significant impair- with impairment of function

severe somnolence,

(>50\% waking hours),

moderate somnolence or $\quad \begin{array}{r}>50 \% \text { waking hours }), \\ \text { agitation, confusion, }\end{array}$ disorientation or hallucinations

dysmetria, slurred speech, locomotor ataxia cerebellar necrosis

severe anxiety or depression

unrelenting and severe

severe

hearing loss interfering

with function but correctable with hearing

$$
\text { aid }
$$

symptomatic subtotal

loss of vision

requires therapy and hospitalis- ation for $>48 \mathrm{hrs}$ after stopping the agent

Paralysis

coma, seizures, toxic psychosis

suicidal ideation

ileus $>96 \mathrm{hrs}$

deafness not correctable

Blindness severe

generalised $>40.0 \mathrm{oC}$ for more than 24 other associated symptoms pronounced or total hair loss

urticaria, drug fever $38 \mathrm{oC}$, mild bronchospasm

pain and swelling with inflammation or phlebitis erythema with pruritus or

symptomatic macular,

papular or vesicular eruption

serum sickness,

bronchospasm requiring Anaphylaxis parenteral medication

ulceration plastic surgery indicated

38.1 - 40.0oC 100.5 -

$>40.0 \mathrm{oC}$ for less than

moderate

$24 \mathrm{hrs}$

hrs or accompanied by

hypotension

severe

life-threatening

exfoliative dermatitis or ulcerating dermatitis

(WHO grading)

severe amponade; drainage
Analogous to Karn
Analogous to fever

analogous to weight gain

analogous to weight loss 


\title{
5.8 Processamento do material
}

\begin{abstract}
5.8.1. Avaliação por HE do tipo histológico e grau tumoral e por imunohistoquímica dos receptores hormonais de estrógeno e progesterona e HER-2.
\end{abstract}

O tipo histológico e o grau tumoral foram avaliados através da peça de biópsia, fixada em parafina cortada com micrótomo, fixada em lâmina de vidro e corada pela técnica de hematoxilina eosina. A avaliação foi realizada através de microscopia óptica comum.

As lâminas de parafina também foram utilizadas para execução da imunohistoquímica com cada anticorpo primário especícifo, a fim de detectarmos e quantificarmos a expressão dos receptores hormonais de estrógeno e progesterona e HER-2. O complexo avidina-biotina peroxidase $(\mathrm{ABC})$ foi utilizado para o ensaio. Resumidamente, utilizamos secção $(4 \mathrm{~mm})$ do bloco de parafina montado em poli-L-lisina, deparafenizada em xilol e fixada em etanol absolutol. Após tratamento com peróxido de hidrogênio $0.3 \%$ em metanol para quelar a atividade das peroxidases endógenas, os cortes foram lavados várias vezes em PBS (phosphate-buffered saline). A imunomarcação foi precedida de incubação com tampão citrato $10 \mathrm{mM}(200 \mathrm{ml} / 20$ cortes $)$ por sete minutos à potencia mais alta do forno de microondas. $\mathrm{O}$ anticorpo monoclonal primário foi específico para cada ensaio. Posteriormente os cortes foram lavados novamente em PBS e recobertos com anticorpo secundário biotinilado anti-mouse por 30 minutos à temperatura ambiente. Após três lavagens adicionais, os cortes foram incubados com o complexo ABC por 60 minutos também à temperatura ambiente. A contra coloração utilizada foi a hematoxilina 
de Harris. Foram utilizados controles positivos e negativos específicos para as substâncias testadas.

\subsubsection{Detecção plasmática dos níveis de VEGF e HIF por ELISA}

Foi colhida uma amostra de $5 \mathrm{ml}$ de sangue das pacientes no momento da coleta da biópsia para separação de plasma, o qual foi aliquotado em frascos de $500 \mu 1$ e armazenados em freezer $-20^{\circ} \mathrm{C}$ até o momento do ensaio. A avaliação foi feita simultaneamente das alíquotas pré e pós quimioterapia para todas as pacientes do estudo, evitando-se assim variação inter-experimental e foram usados kits para ELISA comercialmente disponíveis, todos obtidos da R\&D Systems (USA). Todas as determinações foram realizadas em duplicata e conforme as orientações do fabricante do kit. As análises foram realizadas no Laboratório do Prof. Dr. João Santana da Silva, do departamento de Imunologia, Bioquímica e Parasitologia da Faculdade de Medicina de Ribeirão Preto da Universidade de São Paulo.

\subsection{Análise Estatística}

Para a análise dos resultados, foi utilizado o software GraphPad Prism versão 3.00 da GraphPad Incorporated (San Diego, USA). Os dados são expressos por média \pm desvio padrão (DP). Para todos os testes foi considerado um valor de $\mathrm{P}$ menor do que 0,05 como estatisticamente significativo.

O teste de Shapiro-Wilk W foi utilizado para verificação da distribuição dos valores encontrados de concentração plasmática de VEGF e HIF-1 $\alpha$, e a partir destes 
resultados foram feitas as demais análises estatísticas no presente estudo, que tiveram por objeto confrontar os achados no período pré e pós quimioterapia e correlacionar os mesmos com fatores prognósticos clínicos, histopatológicos e de imunohistoquímica das pacientes, bem como com resposta clínica e histopatológica ao tratamento neoadjuvante.

\section{Resultados}

\subsection{Avaliações clínicas}

Em 6 pacientes (23.1\%), não houve resposta à quimioterapia neo-adjuvante. Nas demais mulheres, todas obtiveram resposta satisfatória com o tratamento quimioterápico, sendo que em 27 a resposta foi parcial, outras três apresentaram resposta completa. Os efeitos adversos de toxicidade ocorreram em 10 casos (38.5\%), porém nenhum caso grave a ponto de contra-indicar a continuidade da terapia primária.

Todas foram encaminhadas para cirurgia pós-tratamento. Com a terapia primária foi possíveis a realização de cirurgia conservadora (tumorectomia oncológica com esvaziamento axilar) em 27 pacientes (75\%) e 7 delas tiveram que ser submetidas a cirurgia radical (mastectomia com esvaziamento axilar). De todas as pacientes, 13 (36.2\%) apresentaram axila comprometida com metástase para 3 ou mais gânglios.

Em relação à recorrência local e a distância, duas pacientes apresentaram recorrência loco-regional e 9 pacientes (incluindo as duas com recidiva local) apresentaram recorrência à distância. Destas pacientes, 6 apresentaram metástase óssea, 2 em pulmão e 2 
com lesão em sistema nervoso central. Ainda ocorreram dois casos de metástase em fígado e ovário. O tempo médio de ocorrência das metástases foi de 18,1 meses. O tempo médio de sobrevida livre de doença das pacientes que não apresentaram nenhum tipo de recorrência foi de 34,8 meses.

Durante o período de acompanhamento, 12 pacientes (33.3\%) foram a óbito em decorrência da doença e o tempo médio de sobrevida destas pacientes foi de 24,2 meses. As demais pacientes apresentam sobrevida global média de 43,7 meses.

Estes dados encontram-se detalhados nas tabelas 2 e 3. Já, as curvas de sobrevida livre de doença e sobrevida global podem ser vistas nos gráficos 1 e 2 . 
Tabela 2. Resposta das 36 pacientes ao tratamento quimioterápico neoadjuvante e implicação cirúrgica do mesmo.

\begin{tabular}{|ccc|}
\hline Características & $\mathrm{n}=36$ & $(\%)$ \\
\hline Resposta a QTX neo & & \\
\hline Com resposta & 6 & 16.7 \\
Toxicidade neo & 30 & 83.3 \\
\hline Tratamento cirúrgico & 10 & 27.7 \\
\hline Conservadora & 29 & 80.5 \\
Radical & 7 & 19.5 \\
\hline Axila negativa & & \\
\hline Status axilar gg positivos & 4 & 11.1 \\
\hline 3 ou + gg positivos & 22 & 61.1 \\
\hline
\end{tabular}

Tabela 3. Evolução das 36 pacientes com carcinoma mamário invasor e submetidas a quimioterapia neoadjuvante e tratamento cirúrgico pós terapia primária.

\begin{tabular}{|l|l|}
\hline Características & $\mathrm{n}=36 \quad(\%)$ \\
\hline Recorrência & \\
\hline
\end{tabular}




\begin{tabular}{|lcc|}
\hline Loco-regional apenas & 0 & 0 \\
Distância apenas & 7 & 19.4 \\
Ambas & 2 & 5.5 \\
\hline Sítios metastáticos & & \\
\hline Osso & 6 & 16.7 \\
Pulmão & 2 & 5.5 \\
Cerebral & 2 & 5.5 \\
Fígado & 1 & 2.7 \\
Ovário & 1 & 2.7 \\
\hline Sobrevida livre doença & & \\
\hline Com recorrência & & \\
\hline Sem recorrência & & \\
\hline Óbito & & \\
\hline Decorrência da doença & & \\
\hline Sobrevida global & & \\
\hline Com recidiva & & \\
\hline & & \\
\hline & & \\
\hline
\end{tabular}

Gráfico 1. Curva sobrevida livre doença de acordo com recorrência loco-regional e à distância. 


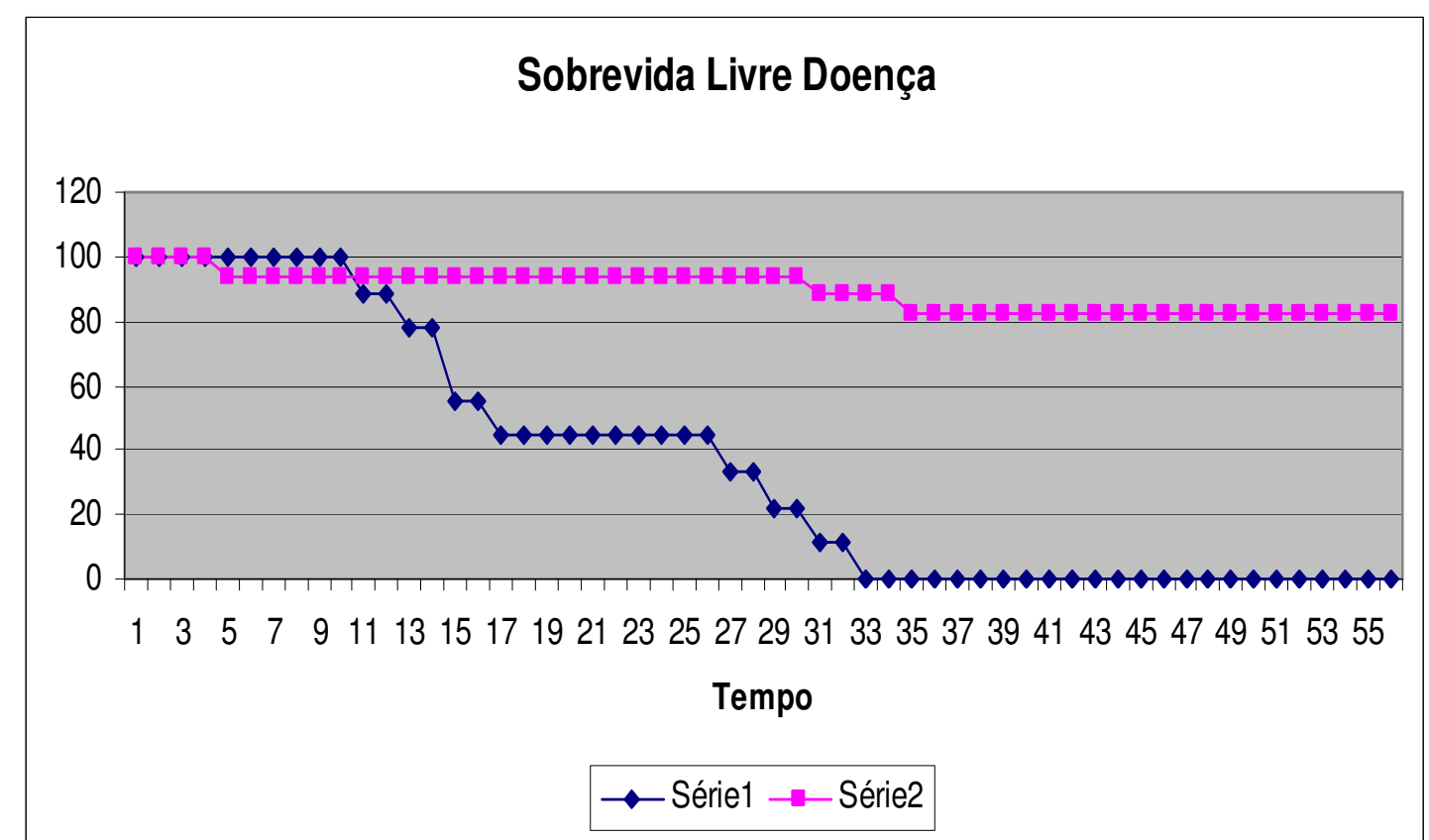

Série 1 = pacientes com meta

Série 2 = pacientes sem meta

Gráfico 2. Curva sobrevida global de acordo com recorrência loco-regional e à distância.

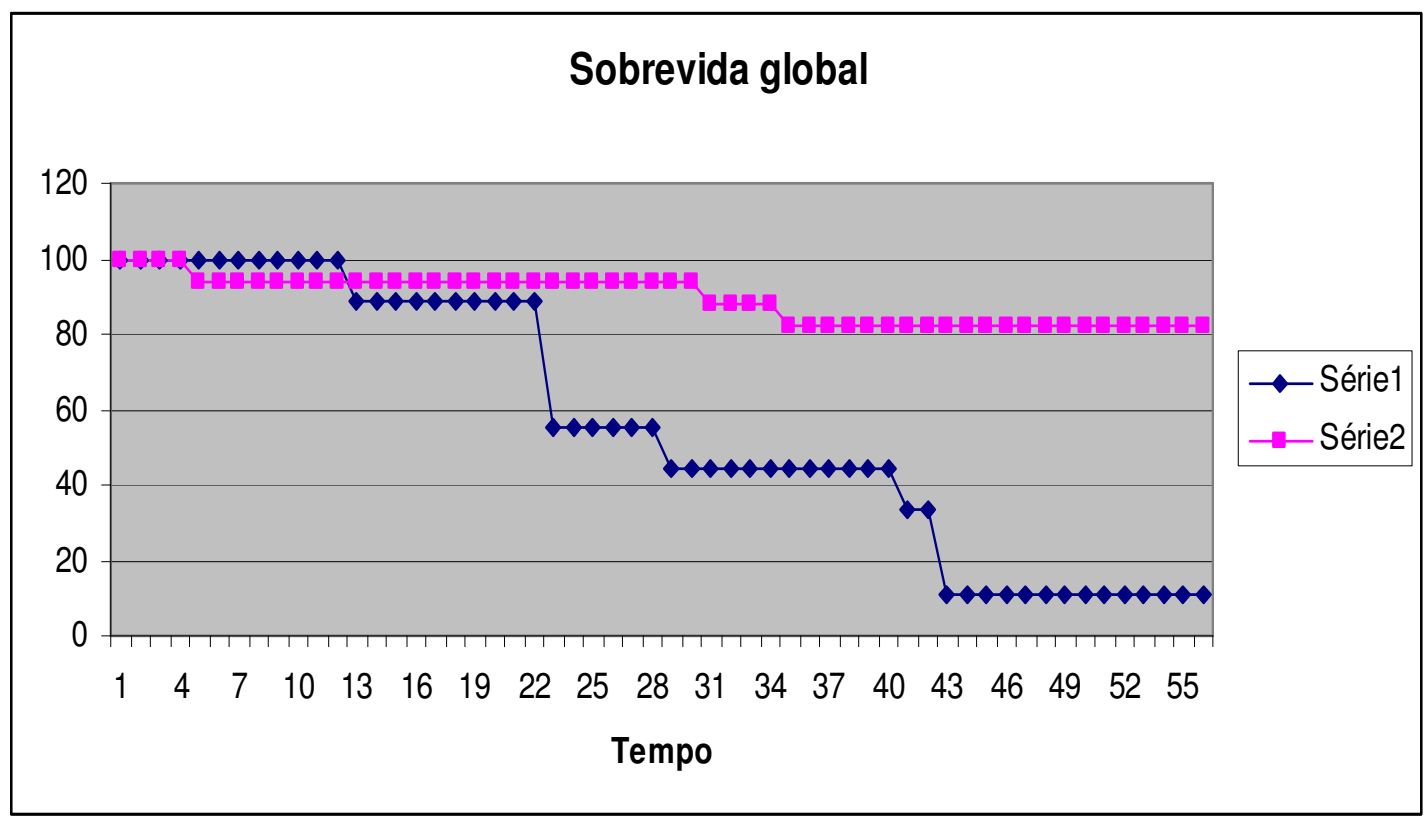

6.2 Série 1 = pacientes com meta Série 2 = pacientes sem metaAvaliações laboratoriais 


\section{Resultados da análise do VEGF.}

Curva Logarítmica da densidade óptica versus concentração plasmática do VEGF em pg/ml obtida pelas concentrações padrões de VEGF fornecidas pelo fabricante (R \& D), utilizada como base de cálculo das dosagens plasmáticas do ensaio.

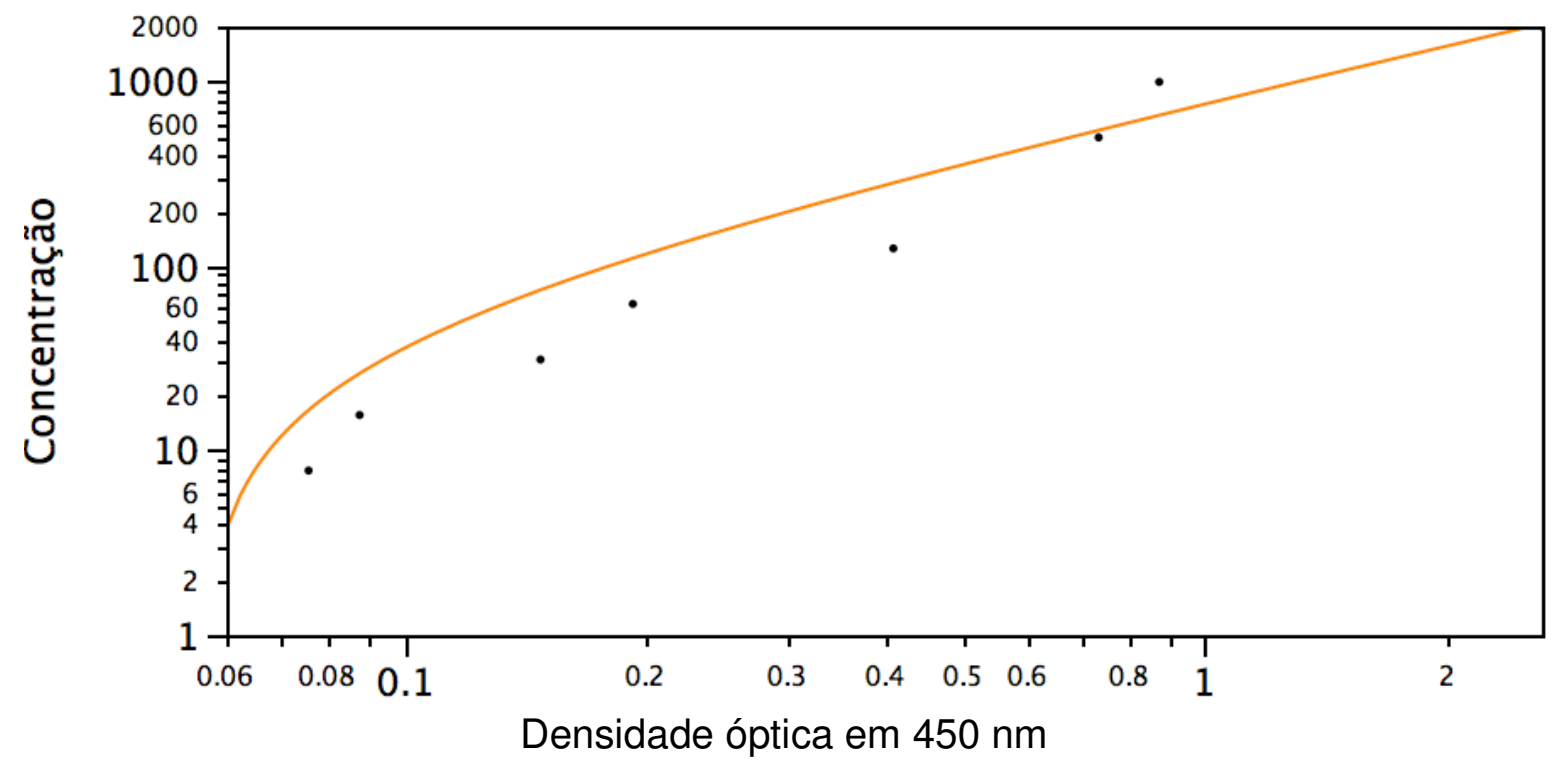

Ajuste linear da curva de concentração

\section{Ajuste linear da curva de concentração para obtenção da equação de calculo daconcentração de VEGF plamático \\ Concentração $=(803.37063 \times$ DO $)-44.45322$}

Distribuição da concentração de VEGF no plasma de pacientes com carcinoma localmente avançado de mama no período pré-quimioterapia. 


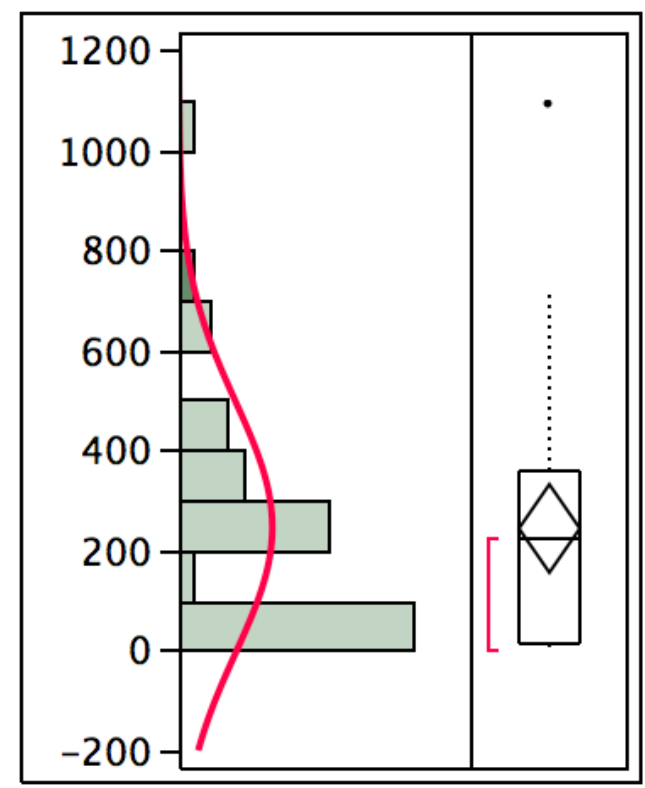

$\operatorname{Normal}(245.26,251.24)$

\section{Quartis}

\begin{tabular}{llr}
\hline $100.0 \%$ & Máximo & 1091.5 \\
\hline $75.0 \%$ & Quartil & 361.3 \\
\hline $50.0 \%$ & Mediana & 225.5 \\
\hline $25.0 \%$ & Quartil & 17.4 \\
\hline $0.0 \%$ & Mínimo & 0.0 \\
\hline
\end{tabular}

\section{Momentos}

\begin{tabular}{lr}
\hline Mediana & 245.26 \\
\hline Desvio Padrão & 251.23987 \\
\hline Erro Médio Padrão & 42.467288 \\
\hline 95\% Mediana Superior & 331.56391 \\
\hline 95\% Mediana Inferior & 158.95609 \\
\hline $\mathrm{N}$ & 36 \\
\hline
\end{tabular}

\section{Ajuste à normalidade}

\begin{tabular}{ccccc}
\hline Tipo & Parâmetro & Estimado & $\begin{array}{l}\text { 95\% do Limite } \\
\text { inferior }\end{array}$ & $\begin{array}{l}\text { 95\% do Limite } \\
\text { superior }\end{array}$ \\
\hline Localização & $\mathrm{M}$ & 245.26 & 158.95609 & 331.56391 \\
\hline Dispersão & $\Sigma$ & 251.23987 & 203.22091 & 329.175 \\
\hline
\end{tabular}

Melhor ajuste pelo teste de Shapiro-Wilk W

\begin{tabular}{rr}
\hline W & Prob $<\mathbf{W}$ \\
\hline 0.853934 & 0.0003 \\
\hline
\end{tabular}

A hipótese do teste seria Ho = Os dados estão dentro de uma distribuição

Normal. Para a rejeição de Ho teríamos o valor de p menor do que o valor do teste, portanto

Ho foi rejeitada e a distribuição dos valores não seguem uma distribuição normal. Assim, as 
análises estatísticas serão realizadas por testes não paramétricos.

Distribuição da concentração de VEGF no plasma de pacientes com carcinoma localmente avançado de mama no período pós-quimioterapia.

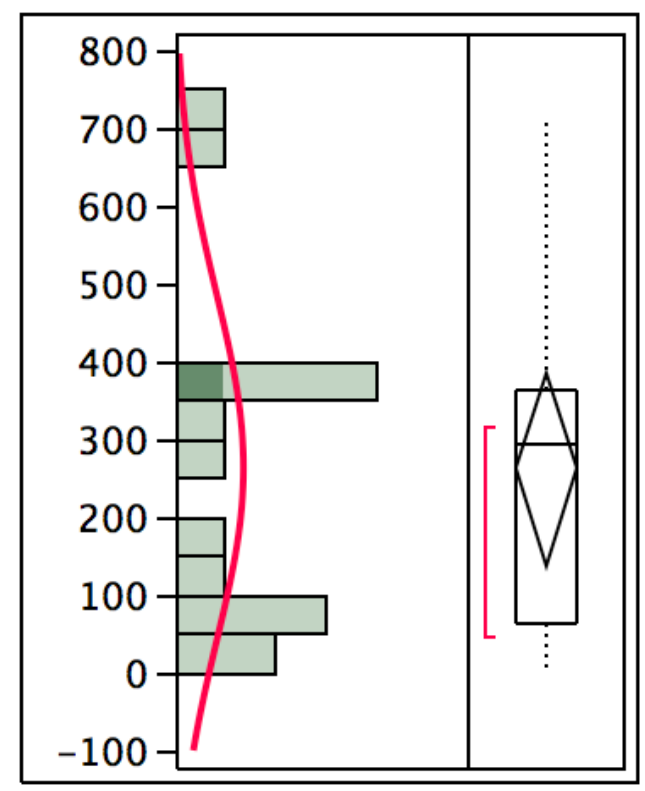

- $\operatorname{Normal}(263.473,222.288)$

\section{Quartis}

\begin{tabular}{llr}
\hline $100.0 \%$ & Máximo & 713.90 \\
\hline $75.0 \%$ & Quartil & 366.90 \\
\hline $50.0 \%$ & Mediana & 294.60 \\
\hline $25.0 \%$ & Quartil & 64.00 \\
\hline $0.0 \%$ & Mínimo & 0.00 \\
\hline
\end{tabular}

\section{Momentos}

\begin{tabular}{lr}
\hline Mediana & 263.47333 \\
\hline Desvio Padrão & 222.28756 \\
\hline Erro Médio Padrão & 57.394402 \\
\hline 95\% Mediana Superior & 386.57208 \\
\hline 95\% Mediana Inferior & 140.37458 \\
\hline $\mathrm{N}$ & 15 \\
\hline
\end{tabular}

Ajuste à normalidade

\begin{tabular}{|c|c|c|c|c|}
\hline Tipo & Parâmetros & Estimado & $\begin{array}{l}95 \% \text { do Limite } \\
\text { inferior }\end{array}$ & $\begin{array}{l}\text { 95\% do Limite } \\
\text { superior }\end{array}$ \\
\hline Localização & $\mathrm{M}$ & 263.47333 & 140.37458 & 386.57208 \\
\hline Dispersão & $\Sigma$ & 222.28756 & 162.74263 & 350.5695 \\
\hline
\end{tabular}

Melhor ajuste pelo teste de Shapiro-Wilk W 


\begin{tabular}{rr}
\hline W & Prob $<\mathbf{W}$ \\
\hline 0.881946 & 0.0507 \\
\hline
\end{tabular}

A hipótese do teste seria Ho = Os dados estão dentro de uma distribuição Normal. Para a rejeição de Ho teríamos o valor de p menor do que o valor do teste, portanto Ho foi rejeitada e a distribuição dos valores não seguem uma distribuição normal. Assim, as análises estatísticas serão realizadas por testes não paramétricos.

Pares relacionados de concentrações plasmáticas de VEGF e suas diferenças entre avaliações pré e pós quimioterapia.

(VEGF pós QT - VEGF pré QT)

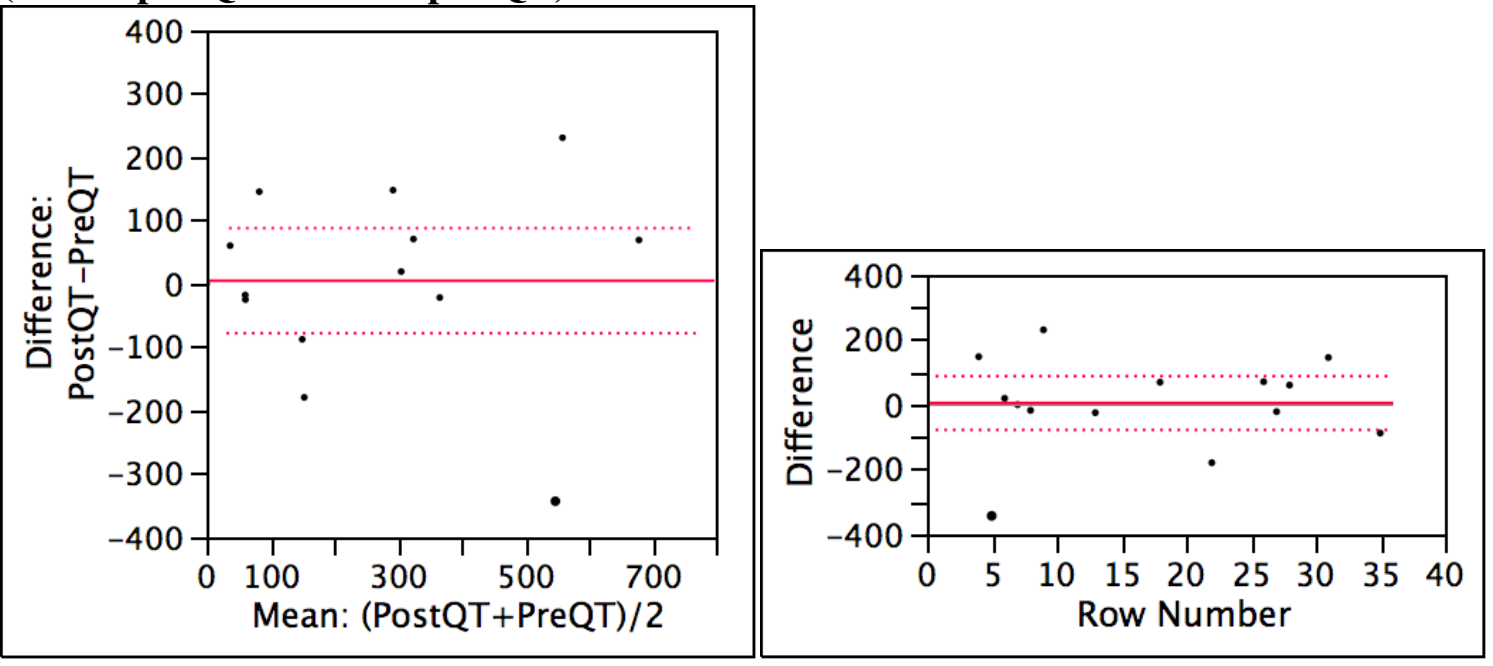

\begin{tabular}{llr}
\hline Post-QT & 261.25 t-Ratio & 0.128135 \\
\hline Pre-QT & 256.329 DF & 13 \\
\hline Diferença Mediana & 4.92143 Prob $>|\mathrm{t}|$ & 0.9000 \\
\hline Erro padrão & 38.4081 Prob $>\mathrm{t}$ & 0.4500 \\
\hline 95\% do Limite superior & 87.8972 Prob $<\mathrm{t}$ & 0.5500 \\
\hline 95\% do Limite inferior & -78.054 & \\
\hline $\mathrm{N}$ & 15 & \\
\hline
\end{tabular}


Correlação 0.80419

Wilcoxon Sign-Rank

\section{PostQT-PreQT}

\begin{tabular}{lr}
\hline Teste estatístico & 5.500 \\
\hline Prob $>$ |z| & 0.7354 \\
\hline Prob $>$ z & 0.3677 \\
\hline Prob $<$ z & 0.6323 \\
\hline
\end{tabular}

Pela análise de correlação não há diferença entre os valores obtidos nos períodos pré quimioterapia comparado com o pós quimioterapia, nas análises do VEGF plasmático.

\section{Resultados da análise do HIF-1a.}

Distribuição da concentração de HIF-1 $\alpha$ no plasma de pacientes com carcinoma localmente avançado de mama no período pré quimioterapia.

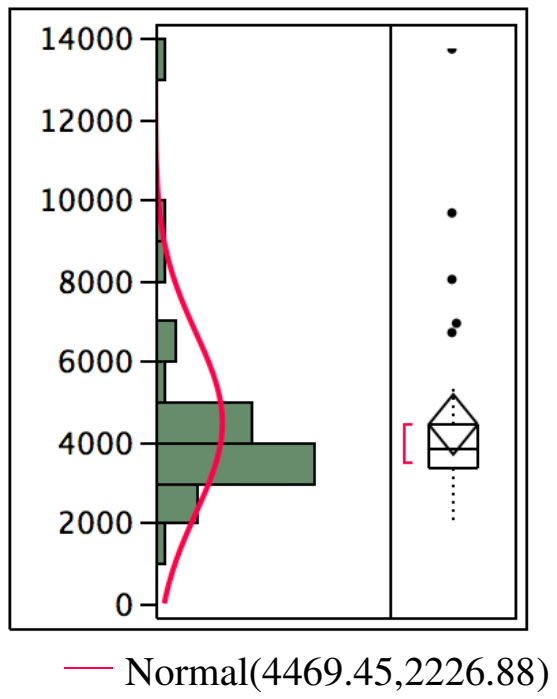

Quartis

\section{Momentos}

\begin{tabular}{llr}
\hline $100.0 \%$ & Máximo & 13716 \\
\hline $75.0 \%$ & Quartil & 4489 \\
\hline $50.0 \%$ & Mediana & 3884 \\
\hline $25.0 \%$ & Quartil & 3385 \\
\hline $0.0 \%$ & Mínimo & 1998
\end{tabular}




\begin{tabular}{lr}
\hline Média & 4469.4486 \\
\hline Desvio padrão & 2226.8781 \\
\hline Erro Médio padrão & 2976.4111 \\
\hline $95 \%$ da Média superior & 5234.408 \\
\hline $95 \%$ da Média inferior & 3704.4892 \\
\hline $\mathrm{N}$ & 36 \\
\hline
\end{tabular}

\section{Ajuste à normalidade}

\begin{tabular}{|c|c|c|c|c|}
\hline Tipo & Parâmetros & Estimado & $\begin{array}{l}95 \% \text { do Limite } \\
\text { inferior }\end{array}$ & $\begin{array}{l}\text { 95\% do Limite } \\
\text { superior }\end{array}$ \\
\hline Localização & $\mathrm{M}$ & 4469.4486 & 3704.4892 & 5234.408 \\
\hline Dispersão & $\Sigma$ & 2226.8781 & 1801.2595 & 2917.6604 \\
\hline
\end{tabular}

Melhor ajuste pelo teste de Shapiro-Wilk W

\begin{tabular}{rr}
\hline W & Prob $<\mathbf{W}$ \\
\hline 0.701575 & $<.0001$ \\
\hline
\end{tabular}

A hipótese do teste seria Ho = Os dados estão dentro de uma distribuição Normal. Para a rejeição de Ho teríamos o valor de p menor do que o valor do teste, portanto Ho foi rejeitada e a distribuição dos valores não segue uma distribuição normal. Assim, as análises estatísticas serão realizadas por testes não paramétricos.

Distribuição da concentração de HIF-1 $\alpha$ no plasma de pacientes com carcinoma localmente avançado de mama no período pós quimioterapia.

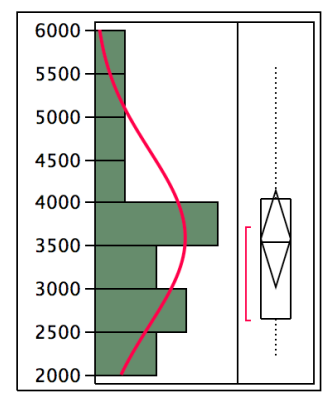

$\operatorname{Normal}(3586.7,1015.94)$

\section{Quartis}

\section{Momentos}

\begin{tabular}{lll}
\hline $100.0 \%$ & Máximo & 5599.4 \\
\hline $75.0 \%$ & Quartil & 4042.4 \\
\hline $50.0 \%$ & Mediana & 3549.5 \\
\hline $25.0 \%$ & Quartil & 2661.9 \\
\hline $0.0 \%$ & Mínimo & 2230.0
\end{tabular}

\begin{tabular}{lr}
\hline Média & 3586.7 \\
\hline Desvio padrão & 1015.9426 \\
\hline Erro Médio padrão & 262.31525 \\
\hline 95\% da Média superior & 4149.3103 \\
\hline 95\% da Média inferior & 3024.0897 \\
\hline $\mathrm{N}$ & 15 \\
\hline
\end{tabular}




\section{Ajuste à normalidade}

\begin{tabular}{|c|c|c|c|c|}
\hline Tipo & Parâmetros & Estimado & $\begin{array}{l}95 \% \text { do Limite } \\
\text { inferior }\end{array}$ & $\begin{array}{l}95 \% \text { do Limite } \\
\text { superior }\end{array}$ \\
\hline Localização & $\mathrm{M}$ & 3586.7 & 3024.0897 & 4149.3103 \\
\hline Dispersão & $\Sigma$ & 1015.9426 & 743.79858 & 1602.2421 \\
\hline
\end{tabular}

Melhor ajuste pelo teste de Shapiro-Wilk W

\begin{tabular}{rr}
\hline W & Prob $<\mathbf{W}$ \\
\hline 0.933418 & 0.3067 \\
\hline
\end{tabular}

A hipótese do teste seria Ho = Os dados estão dentro de uma distribuição Normal. Para a rejeição de Ho teríamos o valor de p menor do que o valor do teste, portanto Ho foi rejeitada e a distribuição dos valores não segue uma distribuição normal. Assim, as análises estatísticas serão realizadas por testes não paramétricos.

Pares relacionados de concentrações plasmáticas de HIF-1 $\alpha$ e suas diferenças entre avaliações pré e pós quimioterapia.

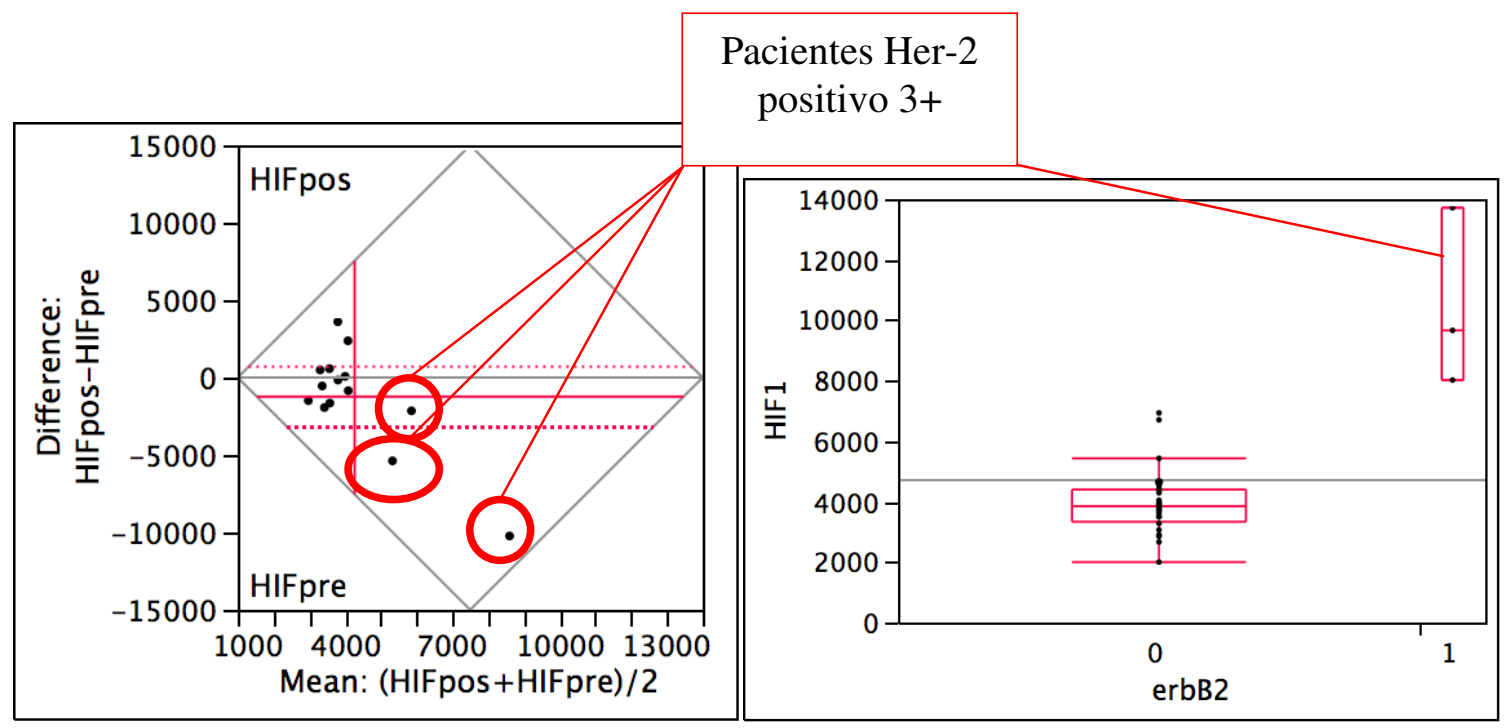




\begin{tabular}{llr}
\hline HIF pós QT & 3652.76 t-Ratio & -1.37827 \\
\hline HIF pré QT & 4886.33 DF & 13 \\
\hline Diferença Mediana & -1233.6 Prob $>$ It & 0.1914 \\
\hline Erro padrão & 895.017 Prob $>\mathrm{t}$ & 0.9043 \\
\hline 95\% do limite superior & 699.995 Prob $<\mathrm{t}$ & 0.0957 \\
\hline 95\% do limite inferior & -3167.1 & \\
\hline $\mathrm{N}$ & 15 & \\
\hline Correlação & -0.2109 & \\
\hline
\end{tabular}

Wilcoxon Sign-Rank

\begin{tabular}{lr}
\hline & HIF pós - HIF pré \\
\hline Teste estatístico & -20.500 \\
\hline Prob $>|\mathrm{z}|$ & 0.2166 \\
\hline Prob $>\mathrm{z}$ & 0.8917 \\
\hline Prob $<\mathrm{z}$ & 0.1083 \\
\hline
\end{tabular}

Pela análise de correlação não há diferença entre os valores obtidos no pré quimioterapia comparado com o pós quimioterapia, nas análises do HIF-1 $\alpha$ plasmático. Já o grupo de pacientes HER-2 positivas apresentou uma forte correlação com um valor de $p=0.0055$.

\section{Correlação com marcadores clínicos e com a sobrevida}

O volume tumoral pré-quimioterapia não apresentou correlação com os valores de VEGF e HIF-1 $\alpha$, detectados no plasma.

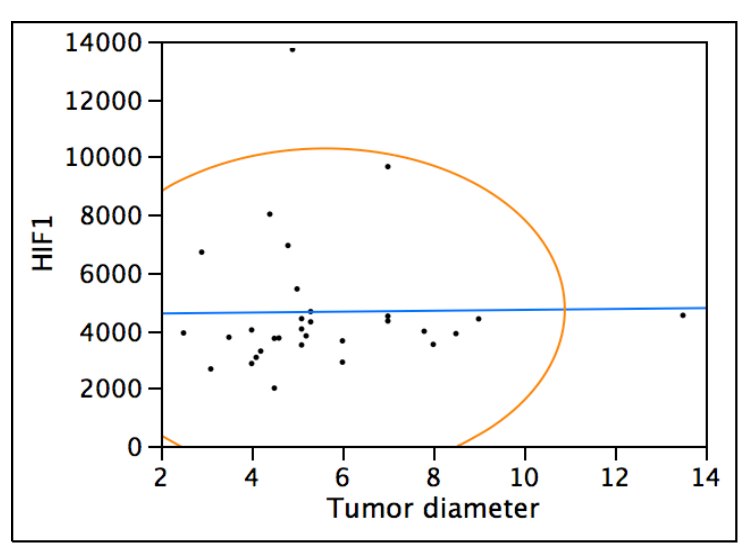

Correlação entre volume tumoral e dosagens plasmáticas de HIF-1 $\alpha$.

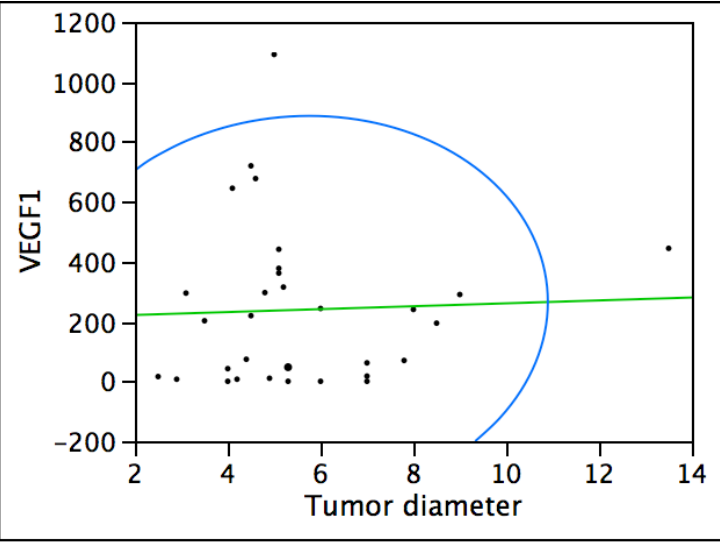

Correlação entre volume tumoral e dosagens plasmáticas de VEGF. 
Os tumores com receptores hormonais de estrógeno e progesterona positivos pela imunohistoquímica (RE+/RP+), que caracterizam um grupo de lesões de melhor prognóstico, apresentaram altas concentrações plasmáticas de VEGF e baixas concentrações de HIF- $1 \alpha$.

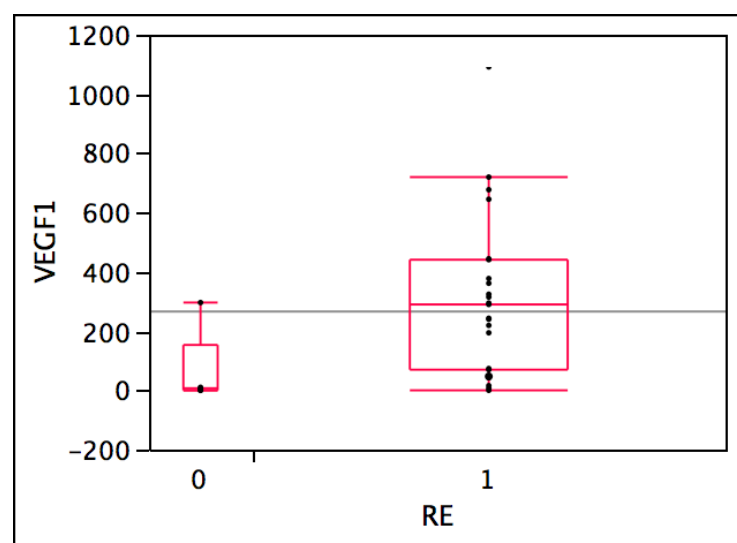

ChiSquare $5.7650 \mathrm{e}$

Prob $>$ ChiSq de 0.0163

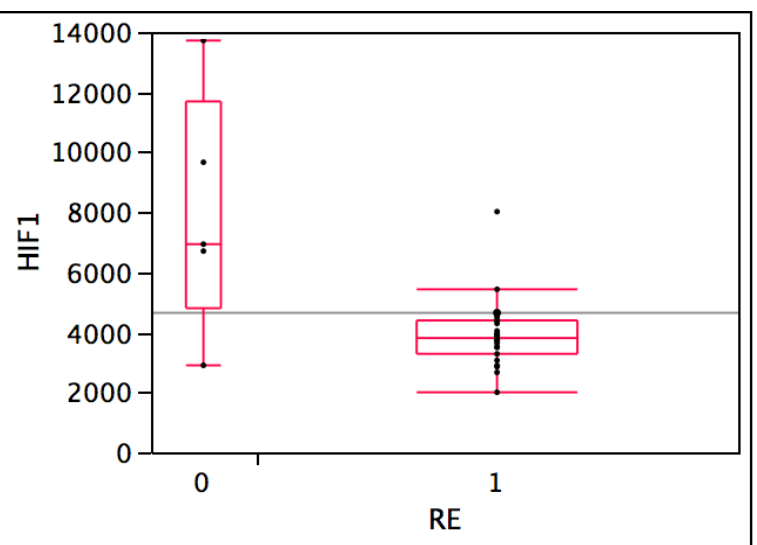

ChiSquare $4.7937 \mathrm{e}$

Prob>ChiSq de 0.0286

Inversamente, os tumores com superexpressão do HER-2, apresentam baixas concentrações plasmáticas de VEGF e altas concentrações do HIF-1 $\alpha$.

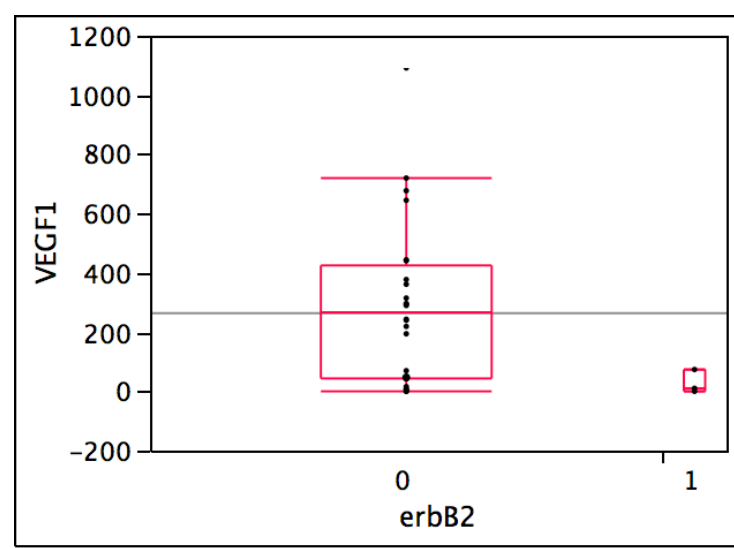

ChiSquare $3.1536 \mathrm{e}$

Prob $>$ ChiSq de 0.0758

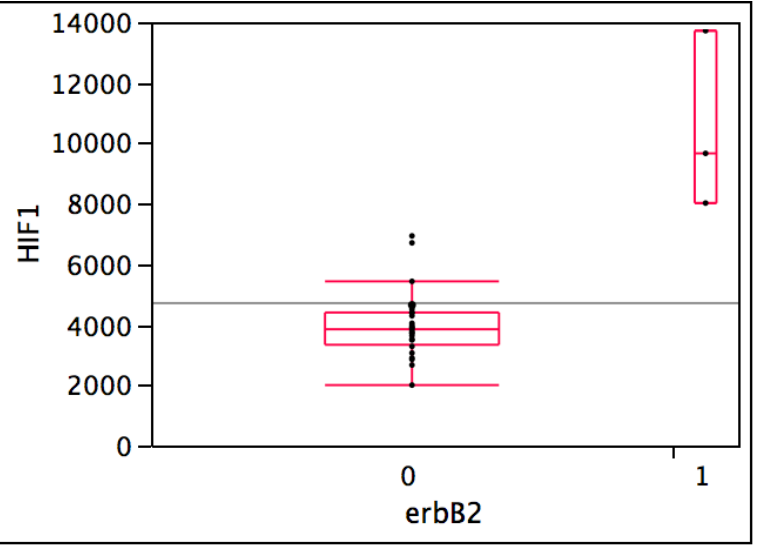

ChiSquare 7.7143e

Prob>ChiSq de 0.0055 
Outro grupo de pacientes especiais, caracterizadas como do grupo basalóide (consideradas como RE e Her-2 negativos), apresentaram concentrações plasmáticas de HIF-1 $\alpha$ mais altas, mas sem diferença estaticamente significante, caracterizando uma tendência, provavelmente relacionada ao pequeno número de casos existentes na análise.

Não encontramos correlação entre as dosagens plasmáticas tanto do VEGF quanto do HIF-1 $\alpha$, quando comparados com outros marcadores clínicos, resposta ao tratamento, ou mesmo a forma de tratamento cirúrgico:
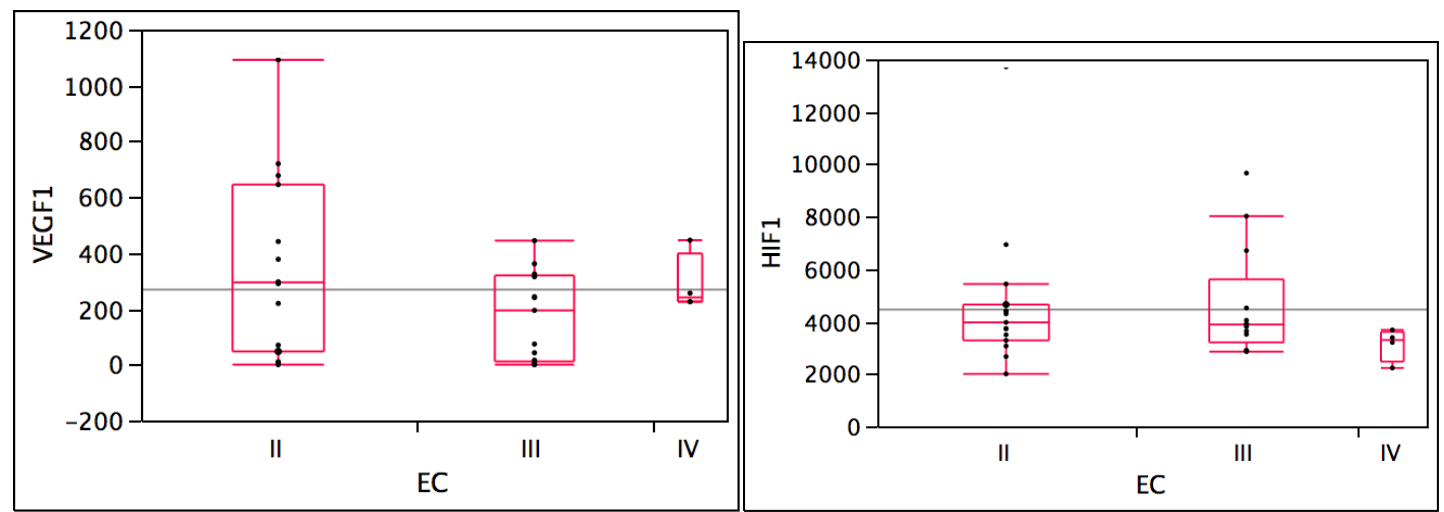

Sem correlação com estádio clínico.
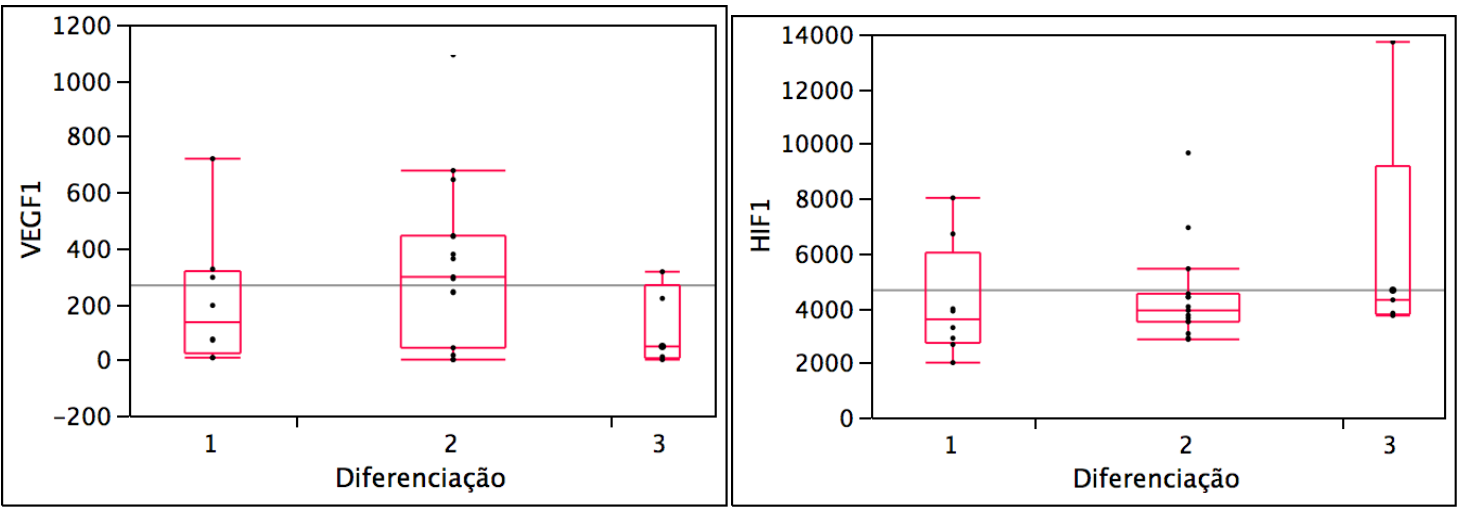

Sem correlação com grau de diferenciação tumoral. 

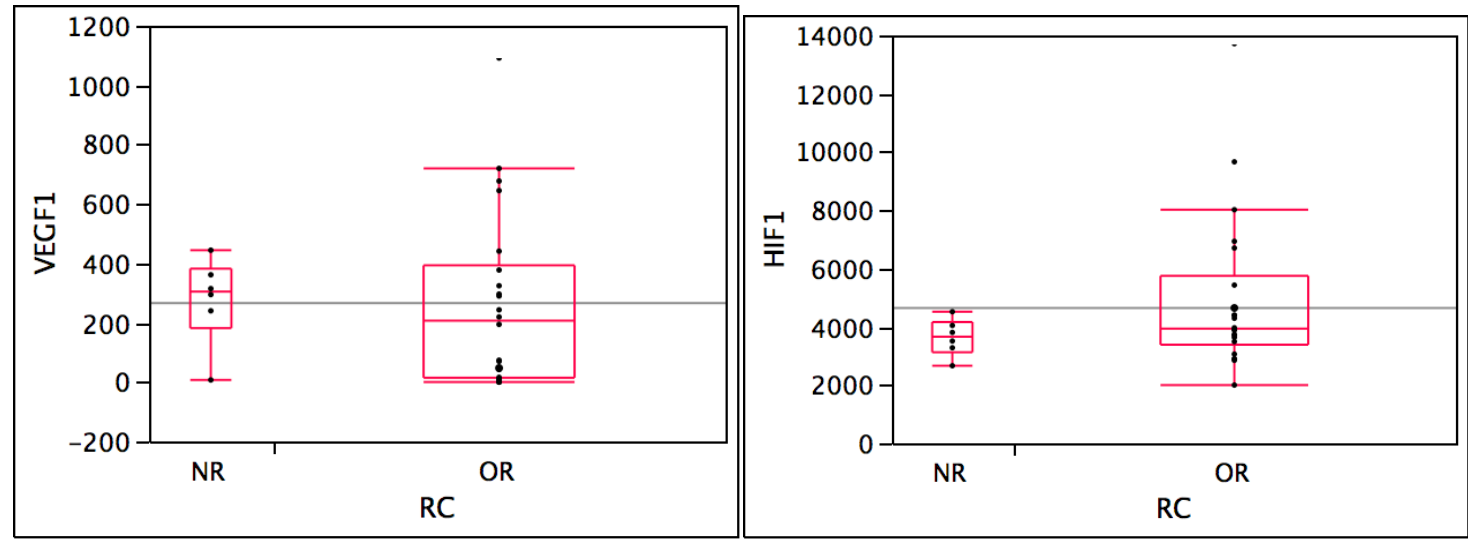

Sem correlação com resposta ao tratamento quimioterápico neoadjuvante.
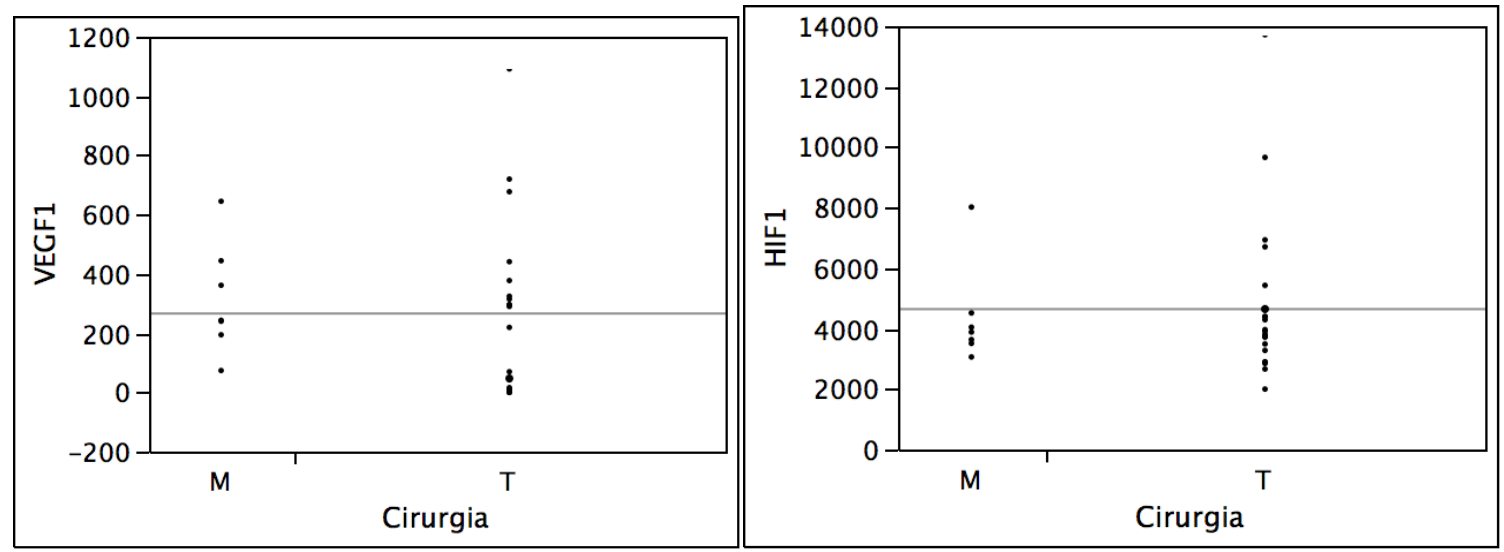

Sem correlação com o tipo da cirurgia realizada ( Mastectomia $=\mathrm{M}$ ou Tumorectomia $=\mathrm{T}$ ).
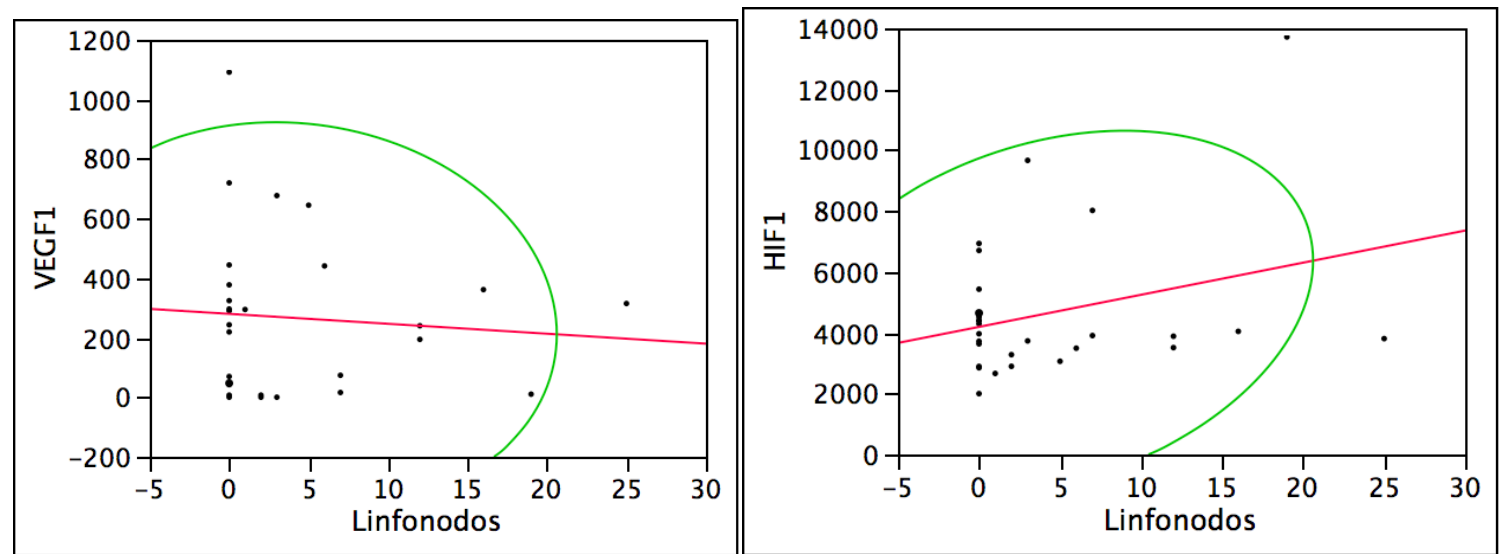

Sem correlação com o comprometimento axilar pó tumor. 
Ao utilizarmos o percentil 90 como ponto de corte na concentração plasmática do HIF-1 $\alpha$, obtivemos uma forte correlação como mau prognóstico na sobrevida das pacientes deste grupo. No entanto, há também neste mesmo grupo uma sobreposição com pacientes Her-2 positivas, e que sabidamente são de pior prognóstico, assim não podemos afirmar que a concentração plasmática do HIF-1 $\alpha$ seja causa do mau prognóstico, mas sim conseqüência deste e que pode servir de marcador prognóstico confiável.

\section{Discussão}

Os carcinomas de mama localmente avançados (CMLA) têm sido considerados um desafio terapêutico dentro da oncologia, posto que o seu prognóstico seja bastante reservado. Entre um terço a metade destas pacientes já se apresentam com comprometimento axilar, refletindo sua agressividade, sendo a sobrevida inversamente relacionada à extensão deste comprometimento axilar e ao volume tumoral (Hortobagyi GN, 1990; Kuerer HM et al., 1999 e Bear HD, 1998; Bear et al., 2006).

A forma mais aceita de se iniciar o tratamento dos CMLA é pela quimioterapia primária ou também chamada de neoadjuvante, que visa conhecer a sensibilidade do tumor às drogas utilizadas, aumentar o número de cirurgias conservadoras da mama, e nos casos de resposta patológica completa, aumentar a sobrevida global (Bear et al., 2006, NSABP -B27).

Durante o processo de crescimento e disseminação tumoral a angiogênese se torna um passo crucial, propiciando não só a oferta de nutrientes essenciais ao crescimento, mas também, uma via de disseminação (Folkman J., 1998; Toi M, et al., 2001). Neste 
sentido, fatores relacionados a angiogênese vêm sendo estudados como marcadores da intensidade deste processo, como o fator de crescimento vascular endotelial (VEGF), que apresenta duas formas solúveis e detectáveis no sangue periférico (Ferrara N, 1999; Ferrara $\mathrm{N}$, et al 2003). Estes valores foram correlacionados tanto com o volume tumoral quanto com o prognóstico de pacientes com câncer de mama (Foekens JA, et al., 2001; Linderholm B, et al 2000). Estudos preliminares mostraram níveis elevados de células endoteliais circulantes em pacientes com carcinoma mamário invasor, e queda destes níveis após aplicação primária de terapia quimioterápica (Frustenberger et al, 2006).

Por outro lado o crescimento tumoral anárquico produz áreas onde a vascularização tem menor penetração, chegando a produzir áreas de necrose por hipóxia nas regiões mais centrais do tumor. Nestas regiões ocorre a produção de um outro fator denominado fator indutor de hipóxia (HIF) que tem um papel crucial na progressão do tumor através de mecanismos regulatórios da angiogênese, sobrevivência celular com baixos níveis de oxigenação, e resistência a drogas (Salceda S, et al., 1997; Huang LE, et al., 1998). Recentemente tem sido responsabilizado pela ativação da expressão do fator de crescimento vascular endotelial (VEGF) (Kimbro \& Simons, 2006).

O volume tumoral tem sido relacionado como um fator determinante das concentrações de VEGF. Existe uma correlação positiva entre lesões carcinomatosas da mama progressivamente maiores e aumento dos valores de VEGF (Bos et al., 2001). Furstenberger et al., (2006) avaliando pacientes em estadios variados, com franca predominância de estadios iniciais, encontrou valores de VEGF de 132 pg/ml para o grupo de tumores e $92 \mathrm{pg} / \mathrm{ml}$ para os controles. Em nossa avaliação não houve correlação significativa entre volume tumoral e valores plasmáticos de VEGF ( $\mathrm{p}=0.736$ ), o que se deve ao fato de termos em nossa casuística somente tumores localmente avançados, e não uma 
variação de tamanhos. Por outro lado, a dosagem do VEGF teve como valor médio 225.5 $\mathrm{pg} / \mathrm{ml}$ (17.4 a 361.3 - percentis $25 \%$ e $75 \%$, respectivamente), valor este muito acima dos $132 \mathrm{pg} / \mathrm{ml}$, variando nos percentis $25 \%$ e $75 \%$ de 106 e $170 \mathrm{pg} / \mathrm{ml}$ respectivamente. Assim é possível inferir que haja realmente esta correlação positiva entre volume tumoral e dosagem plasmática de VEGF, mas que em nosso estudo foi apenas uma tendência. Assim também fica claro que a ausência de mudança nos valores plasmáticos de VEGF no período pós quimioterapia reflete a falta de impacto deste tipo de tratamento na produção deste marcador de angiogênese, ou seja, provavelmente este processo não é afetado pela quimioterapia, mas sim por mudanças de expressão gênica induzidas na população de células tumorais. Isto fica claro se levarmos em conta que, a quimioterapia é um processo de tratamento sistêmico e que não afeta também o processo de angiogênese gerais da economia metabólica de organismo em tratamento.

Os tumores mais bem diferenciados, de menor grau nuclear e citoplasmático estão relacionados à expressão positiva dos receptores hormonais de estrógeno (RE+) e progesterona $(\mathrm{RP}+)$. Estes tumores têm como característica biológica comum um crescimento lento, manter a axila negativa mesmo com tumores localmente avançados e terem melhor prognóstico em termos de sobrevida global e livre de doença. Assim, parece que neste grupo a angiogênese é organizada de forma mais lenta e elaborada, como é a própria biologia do tumor, cursando com níveis mais baixos de VEGF, como detectado em nosso experimento. Por outro lado os tumores HER-2 superexpressos apresentam um crescimento rápido, desorganização estrutural e citológica importantes, axilas extensamente comprometidas, e um pior desempenho em termos de sobrevida global e livre de doença. Assim, os valores de VEGF são mais elevados, pois a angiogênese esta acelerada, e 
diretamente relacionada com este comportamento biológico do tumor, também como detectado em nossa casuística.

A proteína HIF-1 $\alpha$ é superexpressa nos carcinomas primários da mama (Zhong et al.1999). Este aumento da expressão do HIF-1 $\alpha$ é observado tanto nas pacientes Her2 superexpressas quanto nos tumores Her2 negativos (Zhong et al. 1999, Bos et al. 2004). A amplificação gênica do c-erbB2 está associada com um prognóstico ruim e subseqüente resistência à quimioterapia, radioterapia e terapêutica antiestrogênica. A superexpressão do Her2 cursa com o aumento da atividade e da expressão do HIF-1 $\alpha$ in vitro. A produção do VEGF também se encontra elevada nos tumores HER-2 positivos, e as células tumorais Her2-positivas facilitam o processo de vascularização tumoral, em parte pela produção do HIF-1 $\alpha$ (Petit et al. 1997; Laughner et al., 2001; Yen et al., 2002). Altos níveis de expressão de HIF-1 $\alpha$ no câncer de mama humano estão relacionadas à carcinogênese mamária e modificações moleculares decorrentes deste processo. Isto é observado no carcinoma ductal in situ de alto grau que apresenta altos níveis de HIF-1 $\alpha$ (Zhong et al. 1999). No tecido mamário normal não existe produção significativa de HIF1 $\alpha$. Em um estudo retrospectivo envolvendo 745 pacientes, altos níveis de HIF-1 $\alpha$ detectados no diagnostico foi preditivo de recorrência precoce e doença metastática (Dales et al. 2005). O HIF-1 $\alpha$ pôde ser correlacionado com um prognóstico desfavorável nos casos de tumores T1/T2 e axila positiva (Gruber et al. 2004). Bos et al.(2003) sugerem que altos níveis de HIF-1 $\alpha$ tenham um significado borderline no que diz respeito a sobrevida de pacientes com axila negativa.

Em nossa casuística não observamos correlação entre volume tumoral ou axila positiva e níveis mais elevados de HIF-1 $\alpha$, provavelmente pelo mesmo motivo da falta de correlação já mencionado para o VEGF. Nosso grupo de pacientes consiste apenas 
de pacientes com tumores localmente avançados, e com um envolvimento axilar muito importante, onde dois terços delas têm axila positivas e um terço axilas extensamente tomada (mais de três linfonodos), impossibilitando assim uma análise de correlação, já que o grupo este polarizado para o lado do mau prognóstico.

A proteína HER-2 esta definitivamente consolidada como um marcador de mau prognóstico em câncer de mama (Slamon et al., 1987; Rilke et al.,1991; Pegram et al., 1998). Laughner et al. ( 2001) demonstraram que a superexpressão do HER-2 em células 3T3 em camundongos, ou a estimulação de linhagens de células de câncer de mama MCF 7 pela heregulina, resultavam no aumento da expressão de proteínas HIF-1 $\alpha$ e mRNA do VEGF, e que esta expressão era dependente da atividade de PI3K, AKT e FRAP quinase. Em contraste com outros indutores de expressão de HIF-1 $\alpha$, a estimulação pela heregulina do HIF-1 $\alpha$ resulta em uma síntese protéica tal que a combinação da expressão de HER2 e a hipóxia têm um efeito sinérgico na expressão gênica do VEGF (Laughner et al., 2001). Assim, a mediação da angiogênese pela expressão de HIF-1 $\alpha$ pode contribuir diretamente para a letalidade dos tumores HER-2 positivos.

Nossa série de casos apresenta uma limitação importante que é o pequeno número de casos, no entanto estes casos são bastante homogêneos, o que torna os achados bastante consistentes para os casos de tumores de mama localmente avançados. Assim, ao obtermos como resultado valores plasmáticos de HIF-1 $\alpha$ significativamente mais elevados no grupo das pacientes HER-2 positivas, e este grupo apresentar recorrência precoce e sobrevida limitada, encontramos subsidio teórico e experimental para afirmar que estes resultados são verdadeiros e que merecem ser avaliados em novos estudos, já iniciados em nosso grupo de pesquisa. 
Do ponto de vista das vias de expressão gênica encontramos uma correlação interessante em que a ativação do HER-2 em conjunto com o HER-3 e depois com o HER4 vão desembocar na via comum do mTOR, um gene central da angiogênese, que por sua vez esta diretamente relacionado com a ativação do HIF1- $\alpha$, e este ativa a expressão do VEGF.

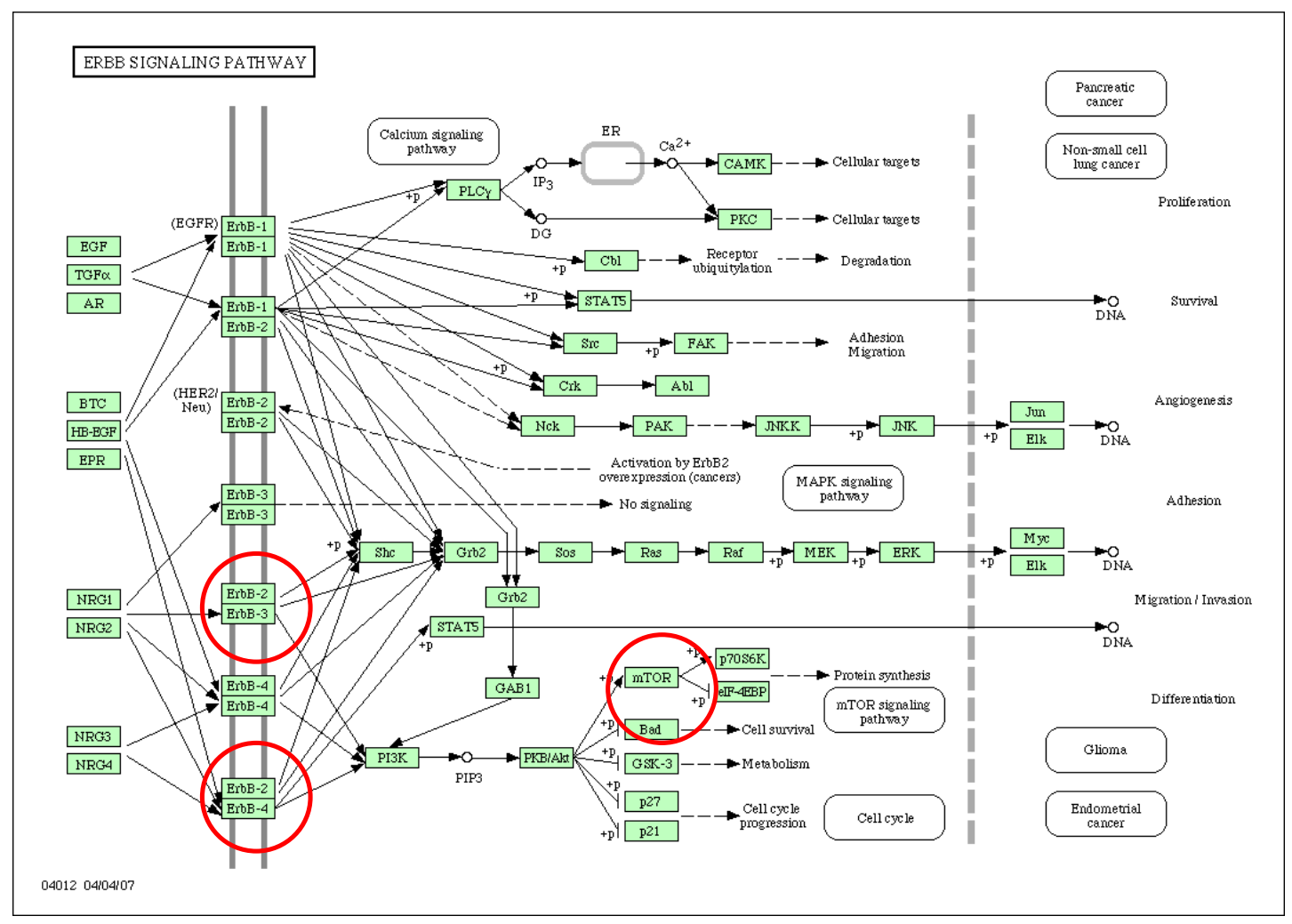

Via de sinalização do HER-2 até o mTOR. 


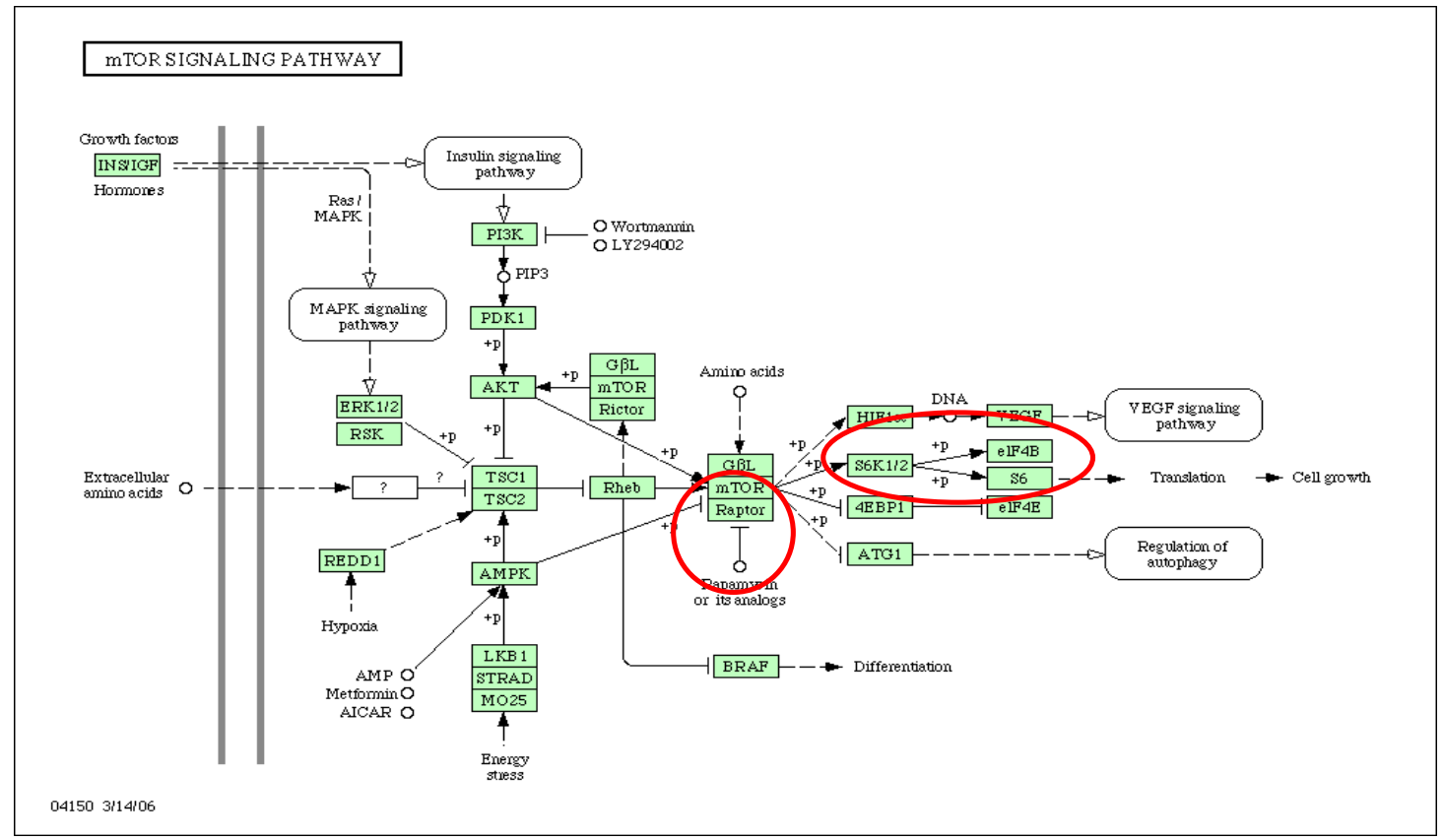

Via de sinalização do mTOR até o VEGF

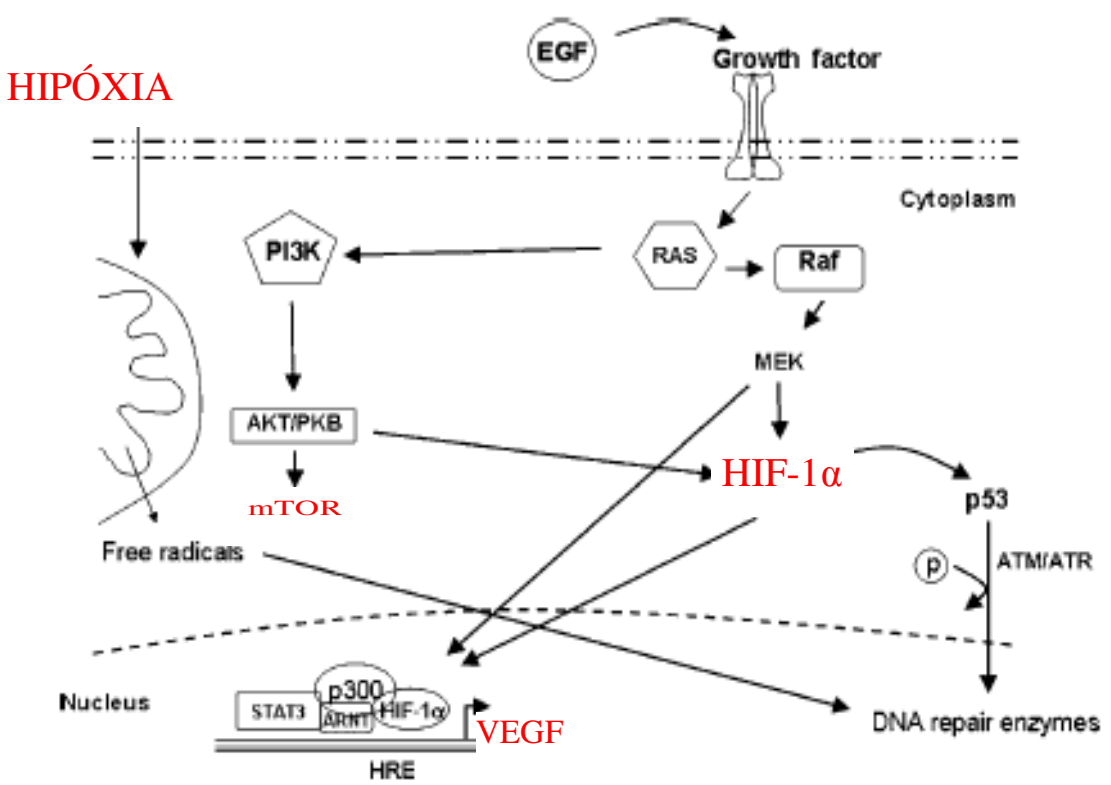

Figure 2 HIF-1 $1 \alpha$ signaling pathway. Hypoxia is signaled by PHDs which in turn release HIF-1 $\alpha$ and redirect HIF-1 $\alpha$ from the proteasome towards the signaling pathway to the nucleus. This pathway is a complex multi-responsive series of different phosphorylations originating from RAS to either PI3K/AKT or RAF/MEKpathway. In tum, HIF-1 $\alpha$ dimerizes with HIF-1B/ARNT and translocates to the nucleus and interacts possibly with STAT3 and p300/CBP to initiate an increase in VEGF tanscription. 
Via de sinalização do HIF-1 $\alpha$. A hipóxia é sinalizada pelos PHDs os quais liberam HIF-1 $\alpha$ e redirecionam HIF-1 $\alpha$ dos proteossomos através de vais de sinalização para o núcleo. Este complexo multi responsivo segue originando diferentes fosforilações pelas vias do RAS até PI3K/AKT ou RAF/MEK. O HIF-1 $\alpha$ dimeriza com o HIF-1 $\beta$ /ARNT e é translocado para o núcleo e interage possivelmente com STAT3 e p300/CBP para iniciar e aumentar a transcrição do VEGF.

\section{Conclus̃̃es}

I. Pela análise de correlação não há diferença entre os valores obtidos nos períodos pré quimioterapia comparado com o pós quimioterapia, nas análises do VEGF e HIF-1 $\alpha$ plasmáticos. Já o grupo de pacientes HER-2 positivas apresentou uma forte correlação nas análises do HIF-1 $\alpha$ plasmático.

II. Os níveis plasmáticos de HIF-1 $\alpha$ apresentam correlação clínica com prognóstico de pacientes com carcinoma localmente avançado da mama. Esta associação se faz através da co-expressão do HER-2, e se sobrepõem a um grupo de pacientes de mau prognóstico. 
III. O VEGF não apresentou relação com o prognóstico, destas pacientes, mas sim uma tendência a se correlacionar com o volume tumoral, tanto no período pré como no pós quimioterapia.

IV. Com relação a intervalo livre de doença e sobrevida global das pacientes, àquelas com fatores de pior prognóstico apresentaram intervalos de tempo bem menores para estes dois parâmetros.

V. A continuidade deste estudo se faz necessária a fim de se consolidar a dosagem plasmática destes marcadores como fatores prognósticos, assim como aprofundar o seu entendimento e compreensão das suas vias de ativação gênica.

\section{Bibliografia}

Ahern, V., Brennan, M., Ung, O., Kefford, R. (2005). Locally advanced and inflammatory breast cancer. Australian Family Physician, 34, 1027-32.

Bear HD: Indications for neoadjuvant chemotherapy for breast cancer. Semin Oncol 25:312, 1998 (suppl 3).

Bos R, van der Groep P, Greijer AE, Shvarts A, Meijer S, Pinedo HM, Semenza GL, van Diest PJ \& van der Wall E Levels of hypoxia-inducible factor-1alpha independently predict prognosis in patients with lymph node negative breast carcinoma. Cancer 97 1573-1581, 2003.

Bos R, van Diest PJ, van der Groep P, Shvarts A, Greijer AE \& van der Wall E 2004 Expression of hypoxia-inducible factor-1alpha and cell cycle proteins in invasive breast cancer are estrogen receptor related. Breast Cancer Research 6 R450-R459. 
Bos R, Zhong H, Hanrahan CF, Mommers ECM, Semenza GL, Pinedo HM, Abeloff MD, Simons JW, van Diest PJ, van der Wall E. Levels of Hypoxia-Inducible Factor-1 $\alpha$ During Breast Carcinogenesis. J Nat Cancer Inst 2001;93:309-14.

Boudreau, N., Myers, C. (2003). Breast cancer-induced angiogenesis: multiple mechanisms and the role of the microenvironment. Breast Câncer Research, 5, 140-6.

Breast cancer risk reduction. Bevers TB, Armstrong DK, Arun B, Carlson RW, Cowan KH, Daly MB, Fleming I, Garber JE, Gemignani M, Gradishar WJ, Krontiras H, Kulkarni S, Laronga C, Lawton T, Loftus L, Macdonald DJ, Mahoney MC, Merajver SD, Seewaldt V, Sellin RV, Shapiro CL, Singletary E, Ward JH; National Comprehensive Cancer Network (NCCN). J Nat Compr Canc Netw. 2007 Sep;5(8):676-701

Dales JP, Garcia S, Meunier-Carpentier S, Andrac-Meyer L, Haddad O, Lavaut MN, Allasia C, Bonnier P \& Charpin C Over expression of hypoxia-inducible factor HIF-1 alpha predicts early relapse in breast cancer: retrospective study in a series of 745 patients. International Journal of Cancer 116 734-739, 2005.

Estimativas da incidência de câncer no Brasil em 2006. Câncer de mama femino http://www.inca.gov.br/estimativa/2006/.

Ferrara N, Gerber HP, LeCouter J: The biology of VEGF and its receptors. Nat Med 9:669676, 2003.

Ferrara N: Molecular and biological properties of vascular endothelial growth factor. $J$ Mol Med 77:527-543, 1999.

Foekens JA, Peters HA, Grebenchtchikov N, Look MP, Meijer-van Gelder ME, GeurtsMoespot A, van der Kwast TH, Sweep CG, Klijn JG: High tumor levels of vascular endothelial growth factor predict poor response to systemic therapy in advanced breast cancer. Cancer Res 61:5407-5414, 2001. 
Folkman J: Role of angiogenesis in tumor growth and metastasis. Semin Oncol. 1998;29:15-18.

Gruber G, Greiner RH, Hlushchuk R, Aebersold DM, Altermatt HJ, Berclaz G \& Djonov V Hypoxiainducible factor 1 alpha in high-risk breast cancer: an independent prognostic parameter? Breast Cancer Research 6 R191-R198, 2004.

Harry D. Bear, Stewart Anderson, Roy E. Smith, Charles E. Geyer, Jr, Eleftherios P. Mamounas, Bernard Fisher, Ann M. Brown, Andre Robidoux, Richard Margolese, Morton S. Kahlenberg, Soonmyung Paik, Atilla Soran, D. Lawrence Wickerham, Norman Wolmark. Sequential Preoperative or Postoperative Docetaxel Added to Preoperative Doxorubicin Plus Cyclophosphamide for Operable Breast Cancer: National Surgical Adjuvant Breast and Bowel Project Protocol B-27. Journal of Clinical Oncology, Vol 24, No 13 (May 1), 2006: pp. 2019-2027.

Hayward JL, Carbone PP, Heusen JC, Kumaoka S, Segaloff A, Rubens RD. Assessment of response to therapy in advanced breast cancer. Br J Cancer, 1977: 35, 292-8.

Hortobagyi GN: Comprehensive management of locally advanced breast cancer. Cancer 66:1387- 391, 1990 (suppl 6).

Huang LE, Gu J, Schau M, Bunn HF. Regulation of hypoxia-inducible factor 1 a is mediated by an O2-dependent degradation domain via the ubiquitin-proteasome pathway. Proc Natl Acad Sci USA 1998;95:7987-92.

International Union Against Cancer: Introduction UICC Global Cancer Control. Geneve, Switzerland, UICC, 2005.

Kimbro K S \& Simons J W. Hypoxia-inducible factor-1 in human breast and prostate cancer. Endocrine-Related Câncer; 2006, 13 739-749. 
Kuerer HM, Newman LA, Smith TL, et al: Clinical course of breast cancer patients with complete pathologic primary tumor and axillary lymph node response to doxorubicinbased neoadjuvant chemotherapy. J Clin Oncol 17:460-469, 1999

Laughner E, Taghavi P, Chiles K, Mahon PC \& Semenza GL. HER2 (neu) signaling increases the rate of hypoxiainducible factor 1alpha (HIF-1alpha) synthesis: novel mechanism for HIF-1-mediated vascular endothelial growth factor expression. Molecular and Cellular Biology 21 3995-4004, 2001.

Linderholm B, Grankvist K, Wilking N, Johansson M, Tavelin B, Henriksson R: Correlation of vascular endothelial growth factor content with recurrences, survival, and first relapse site in primary node-positive breast carcinoma after adjuvant treatment. $J$ Clin Oncol 18:1423-1431, 2000.

Pegram MD, Pauletti G, Slamon DJ.. HER-2/neu as a predictive marker of response to breast cancer therapy. Breast Cancer Res Treat 52:65-77, 1998.

Petit AM, Rak J, Hung MC, Rockwell P, Goldstein N, Fendly B \& Kerbel RS Neutralizing antibodies against epidermal growth factor and ErbB-2/neu receptor tyrosine kinases down-regulate vascular endothelial growth factor production by tumor cells in vitro and in vivo: angiogenic implications for signal transduction therapy of solid tumors. American Journal of Pathology 151 1523-1530, 1997.

Pradeep, C.R., Sunila, E.S., Kuttan, G. (2005). Expression of Vascular Endothelial Growth Factor (VEGF) and VEGF Receptors in Tumor Angiogenesis and Malignancies. Integrative Câncer Therapies, 4, 315-21.

Rilke F, Colnaghi MI, Cascinelli N, Andreola S, Baldini MT, Bufalino R, Della Porta G, Menard S, Pierotti MA, Testori A. Prognostic significance of HER-2/neu expression in breast cancer and its relationship to other prognostic factors. Int J Cancer 49:44-49, 1991. 
Rosen, S.L. (2005). VEGF-Targeted therapy: therapeutic potential and recent advances. Oncologist, 10, 382-91.

Sachelarie, I., Grossbard, M.L., Chadha, M., Feldman, S., Ghesani, M., Blum, R.H. (2006). Primary Systemic Therapy of Breast Câncer. The Oncologist, 11, 574-89.

Salceda S, Caro J. Hypoxia-inducible factor 1a (HIF-1 a) protein is rapidly degraded by the ubiquitin-proteasome system under normoxic conditions. Its stabilization by hypoxia depends on redox-induced changes. J Biol Chem 1997; 272:22642-7.

Schoppmann, S.F., Birner, P., Sto"ckl, J., Kalt, R., Ullrich, R., Caucig, C., Kriehuber, E., Nagy, K., Alitalo, K., Kerjaschki, D. (2002). American Journal of Pathology, 16, 94756.

Slamon DJ, Clark GM, Wong SG, Levin WJ, Ullrich A, McGuire WL.. Human breast cancer: correlation of relapse and survival with amplification of the HER-2/neu oncogene. Science 235:177-182, 1987.

Toi M, Matsumoto T, Bando H: Vascular endothelial growth factor: its prognostic, predictive, and therapeutic implications. Lancet Oncol 2:667-673, 2001.

Yen L, Benlimame N, Nie ZR, Xiao D, Wang T, Al Moustafa AE, Esumi H, Milanini J, Hynes NE, Pages G et al. Differential regulation of tumor angiogenesis by distinct ErbB homo- and heterodimers. Molecular Biology of the Cell 13 4029-4044, 2002.

10.Zhong H, De Marzo AM, Laughner E, Lim M, Hilton DA, Zagzag D, Buechler P, Isaacs WB, Semenza GL \& Simons JW 1999 Over expression of hypoxia-inducible factor 1alpha in common human cancers and their metastases. Cancer Research 59 5830-5835. Apêndice 

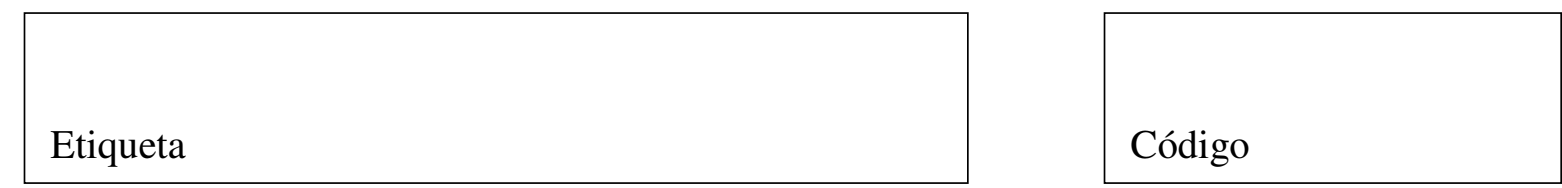

Idade:

Estadio:

$\mathrm{T}$

$\mathrm{N}$

M

EC

Trat. Ppto:

Trat. Real:

Data dos Atend.:

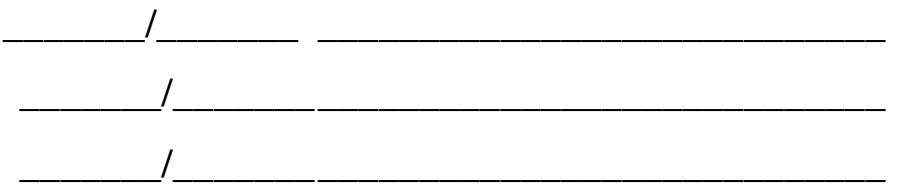

Avaliação ao final do Tratamento:

Status Axilar:

$+1$

Data da Biópsia:

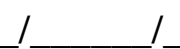

Número da Biópsia:

Histologia:

Outros materiais enviados:

Material armazenado no laboratório de Imunologia:

IDENTIFICAÇÃO RACK CAIXA DATA

MATERIAL

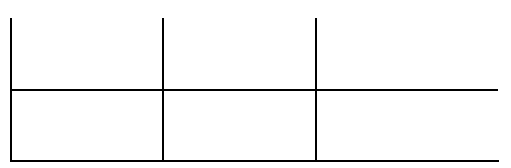

11. Termo de Consentimento Livre e Esclarecido 
Hospital das Clínicas da Faculdade de Medicina de Ribeirão Preto da Universidade de São Paulo

TERMO DE CONSENTIMENTO LIVRE E ESCLARECIDO

$\mathrm{Eu}$, abaixo assinado, tendo sido devidamente esclarecida sobre todas as condições que constam do documento "ESCLARECIMENTO AO SUJEITO DA PESQUISA", de que trata o projeto de pesquisa intitulado "Produção de VEGF e HIF-1 $\alpha$ em Pacientes com Carcinoma de Mama Localmente Avançado submetidas à Quimioterapia Neoadjuvante", que tem como pesquisador responsável o Sr. Alexandre Pavan Garieri, especialmente no que diz respeito ao objetivo da pesquisa, aos procedimentos que serei submetido, aos riscos e aos benefícios, à forma de ressarcimento no caso de eventuais despesas, bem como a forma de indenização por danos decorrentes da pesquisa, declaro que tenho pleno conhecimento dos direitos e das condições que me foram assegurados, a seguir relacionados:

1. A garantia de receber a resposta a qualquer pergunta ou esclarecimento de qualquer dúvida a respeito dos procedimentos, riscos, benefícios e de outras situações relacionadas com a pesquisa e o tratamento a que serei submetido.

2. A liberdade de retirar o meu consentimento e deixar de participar do estudo, a qualquer momento, sem que isso traga prejuízo à continuidade do meu tratamento.

3. A segurança de que não serei identificado e que será mantido o caráter confidencial da informação relacionada a minha privacidade.

4. O compromisso de que me será prestada informação atualizada durante o estudo, ainda que esta possa afetar a minha vontade de continuar dele participando.

5. O compromisso de que serei devidamente acompanhada e assistida durante todo o período de minha participação no projeto, bem como de que será garantida a continuidade do meu tratamento, após a conclusão dos trabalhos de pesquisa.

Declaro, ainda, que concordo inteiramente com as condições que me foram apresentadas e que, livremente, manifesto a minha vontade em participar do referido projeto.11.

\section{Esclarecimento ao Sujeito da Pesquisa}


Sra eu, Dr. Alexandre Pavan Garieri, peço a sua autorização para incluí-la na pesquisa "Produção de VEGF e HIF-1 $\alpha$ em Pacientes com Carcinoma de Mama Localmente Avançado submetidas à Quimioterapia Neoadjuvante”.

Esta pesquisa tem como objetivo estudar as alterações de substâncias no sangue e no tumor em mulheres com câncer de mama submetidas a quimioterapia. Não faremos nenhum exame ou cirurgia por causa da pesquisa, apenas aproveitaremos $5 \mathrm{ml} \mathrm{de}$ sangue e um fragmento do tumor, retirados durante os procedimentos de quimioterapia e da cirurgia mamária, realizados para o tratamento de seu problema de saúde.

Garantimos que seu nome não será exposto em nenhuma apresentação ou qualquer tipo de publicação e que a senhora poderá deixar de participar da pesquisa em qualquer momento que desejar. Caso a senhora não concorde com a participação no estudo ou deseje sair do mesmo, não haverá prejuízo em seu tratamento e seguimento. Ressaltamos ainda que a senhora terá liberdade de retirar este consentimento em qualquer momento que desejar sem prejuízo para o seu tratamento e seguimento neste serviço e que estamos a disposição para maiores esclarecimentos a qualquer momento que a senhora desejar.

Ribeirão Preto, de de 2004.

\section{Assinatura da Paciente}

Dr. Alexandre Pavan Garieri - Pesquisador Responsável 